\title{
MEMORIAS EN ACCIÓN. \\ UN NIÑO EN LA REVOLUCIÓN MEXICANA \\ DE ANDRÉS IDUARTE FOUCHER ${ }^{1}$
}

\author{
Fabio Kolar \\ Universidad de Hamburgo
}

\section{INTRODUCCIÓN}

"He podido realizar el milagro de vivir físicamente lejos de México y estar allá presente todos los días", ${ }^{2}$ escribió Andrés Iduarte Foucher, no sin orgullo, en una carta a un amigo. El reconocido escritor tabasqueño, que nació el $1^{\circ}$ de mayo de 1907 en Villahermosa, pasó su niñez y juventud en México, donde fue testigo de la revolución mexicana (1910-1940), pero la mayor parte de su vida vivió lejos de

Fecha de recepción: 27 de mayo de 2015

Fecha de aceptación: 28 de agosto de 2015

${ }^{1}$ Por sus comentarios críticos y correcciones útiles quisiera agradecer en particular a Marta Eugenia García Ugarte, Ulrich Mücke, Lorena Pérez Hernández, María Cristina Simón Ruiz y Guillermo Zermeño Padilla. La base de este artículo fue un corto texto electrónico publicado en alemán, del cual fueron extraídos algunos argumentos y párrafos. Kolar, "Erinnern, erzählen, bekennen”.

2 Iduarte, "Carta a un buen amigo", p. 45. 
su patria: en Francia, en España y, en particular, en Estados Unidos.

Después de terminar la carrera de Derecho en la Universidad Nacional de México, Iduarte se fue por dos años a París, en donde continuó con sus estudios. En 1930 regresó a México para incorporarse como profesor de Historia en la Escuela Nacional Preparatoria. Entre sus alumnos estuvo Octavio Paz. En aquellos años se desempeñó también como director de la revista Universidad de México. En 1933, Iduarte se embarcó para Madrid. Mientras obtenía el doctorado en Derecho en la Universidad Central de Madrid, abogó como periodista y escritor por la Segunda República. Tanto en Francia como en España estableció relaciones con escritores reconocidos como Miguel Ángel Asturias, César Vallejo, Gabriela Mistral, Pablo Neruda, Rómulo Gallegos y Jorge Carrera Andrade. En junio de 1938, Iduarte salió de España rumbo a Nueva York, en donde trabajaría - con interrupciones menores - durante 35 años en el famoso Instituto Hispánico de la Universidad de Columbia. Al inicio fue estudiante y docente, más tarde fue catedrático de Literatura Hispanoamericana. En esa misma institución obtuvo un segundo doctorado con una tesis sobre José Martí. Entre 1952 y 1954, el tabasqueño se encargó de la dirección del Instituto Nacional de Bellas Artes en la ciudad de México. Sin embargo, terminó su gestión antes de tiempo por un escándalo político: Iduarte permitió que el velorio de Frida Kahlo tuviera lugar en el Palacio de Bellas Artes, donde Diego Rivera y los miembros del Partido Comunista Mexicano utilizaron políticamente el acto al extender una bandera soviética sobre el ataúd; Iduarte no pudo, o tal vez no quiso, impedirlo. En consecuencia, fue suspendido de su cargo 
y volvió, otra vez, a Nueva York, en donde permanecería hasta que se jubiló en la misma Universidad de Columbia en 1975. Los últimos años de su vida los pasó en la ciudad de México. Falleció el 16 de abril de 1984. ${ }^{3}$

Aunque vivió tantos años en el extranjero, Iduarte nunca dejó de preocuparse por su país natal. En su plática y en su escritura, México siempre estaba presente. Además representaba en Nueva York al Estado mexicano en diferentes funciones oficiales. ${ }^{4}$ Por lo tanto, solía responder a quienes lo creyeran separado de sus raíces y sumergido en un mundo ajeno: "Vivo en nuestra tierra y con nuestra gente tanto como ustedes, y más que muchos de ustedes". ${ }^{5}$

La tensión entre ausencia y presencia marca la escritura de Iduarte y confiere a su obra un acento nostálgico. ${ }^{6} \mathrm{Su}$ libro más conocido es, sin duda, Un niño en la Revolución Mexicana, ${ }^{7}$ considerado ya como un clásico de la narrativa sobre la epopeya revolucionaria. El autor cuenta su infancia en el escenario turbulento de la Revolución. La narración

${ }^{3}$ Véase en relación con la vida de Iduarte, Mandujano Jacoвo, “Andrés Iduarte” у SAсото, “Andrés Iduarte”. La historia del escándalo político es trabajado literariamente por GaOnA, Andrés y Diego.

${ }^{4}$ Iduarte trabajó, en sus mismas palabras, "primero como becario de la Secretaría de Educación Pública y luego como conferenciante del Departamento de Turismo de Nueva York, mientras era estudiante de Columbia University y hasta que obtuve el doctorado en Filosofía y Letras; después, como representante de la Secretaría del Trabajo, y desde 1949 como miembro permanente de la delegación de México ante las Naciones Unidas”. Iduarte, “México en Nueva York”, p. 69.

${ }^{5}$ Iduarte, "Presencia de los ausentes", p. 21.

${ }^{6}$ Significativamente, Iduarte le dio a una colección de ensayos suyos el título de México en la nostalgia. Véase IDUarTe (comp.), México en la nostalgia.

7 IdUarte, Un niño en la Revolución Mexicana. 
es la primera parte de un ciclo de cuatro obras autobiográficas proyectadas. Sin embargo, sólo fue publicado otro libro más: El mundo sonriente. ${ }^{8}$ Varios investigadores han subrayado la importancia de las memorias de Iduarte. Para Rogelio Rodríguez Coronel se trata de "textos altamente significativos". ${ }^{9}$ Víctor Díaz Arciniega habla al respecto de "textos de índole autobiográfica cuya importancia es fundamental". ${ }^{10}$ No obstante, faltan, con unas excepciones notables, estudios que se ocupen críticamente de la obra de Iduarte. ${ }^{11}$ De ahí el interés por proponer un estudio que contribuya a completar esta laguna de investigación. Además quisiera abogar por extender la investigación historiográfica al todavía poco utilizado fondo de fuentes

8 IDUARTE, El mundo sonriente. "Otra vez París” y "Bajo el sol del diablo", que deberían continuar el relato de la vida de Iduarte, lamentablemente, nunca fueron acabadas ni publicadas.

9 Rodríguez Coronel, “Andrés Iduarte”, p. 105.

10 Díaz Arciniega, "La voz: el eco", p. 758. Para ser preciso: la cita se refiere a un corpus de obras autobiográficas que incluye Un niño en la Revolución Mexicana.

${ }_{11}$ Aparte de los ya mencionados e informativos trabajos de Rodríguez Coronel, “Andrés Iduarte”, y Díaz Arciniega, “La voz: el eco", se deben mencionar los siguientes estudios. No obstante, la mayoría de ellos se centran más en la persona que en la obra de Iduarte, y, a veces, son poco críticos: Keller, "El niño en la Revolución Mexicana"; Keller y VAN Hooft, "Las actividades políticas"; Beer, "Visión de España"; Rовв, "México en la nostalgia"; Ocampo Ramírez, "Andrés Iduarte"; Orestes Aguilar, "Andrés Iduarte”; Avilés Fabila, "Un niño en la Revolución Mexicana". Además se debe mencionar el siguiente homenaje: Grass (comp.), Andrés Iduarte. Más allá de esto se puede nombrar la aportación de Morales, "En el centenario de Andrés Iduarte". Recientemente fue publicado el interesante trabajo de Sosenski y Osorio Gumá, "Memorias de infancia”. 
autobiográficas $^{12}$ y también a las narraciones menos conocidas para hacer justicia a la pluralidad histórica mexicana. ${ }^{13}$

Al contrario de lo que se podría pensar, no es la intención de esta investigación indagar sobre la vida de los niños en la revolución mexicana - tema que ha llamado recientemente la atención de los historiadores.$-{ }^{14}$ Un niño en la Revolución Mexicana podría ser una fuente interesante para el estudio de la infancia en México, como lo muestran Susana Sosenski y Mariana Osorio Gumá. Las investigadoras reflexionan sobre "las formas en que la tragedia de la muerte se imbricó en la vida cotidiana, en el tejido social o en las experiencias de vida de los niños que asistieron al drama de la guerra”. Aprovechan el texto autobiográfico de Iduarte para acercarse "a la memoria y a la representación de las experiencias infantiles” en la revolución mexicana. ${ }^{15}$ Aquí, sin embargo, se propone una lectura diferente del texto. No se trata de responder a la pregunta de cómo vivía y experimentaba Iduarte su infancia, sino de por qué y cómo el tabasqueño narraba la misma. Es decir, se fija en la construcción de identidad realizada por Iduarte por medio

12 Richard D. Woods presenta en una bibliografía indispensable sobre la escritura autobiográfica en México más de 1900 títulos. Véase Woods, Autobiographical Writings.

13 Angelika Schaser ya ha formulado este argumento para el contexto alemán. Véase Schaser, "Einleitung”.

14 Véase, por ejemplo, Alcubierre Moya y Carreño King, Los niños villistas; CARreño KING (comp.), Infancia y revolución; GUERRERO FLORES, "Valoración del trabajo infantil”; MEYER, “¿Dónde están los niños?”; Sosenski y Jackson Albarrán (comps.), Nuevas miradas a la historia de la infancia.

15 Sosenski y Osorio Gumá, “Memorias de infancia”, pp. 154 y 156. 
de la escritura autobiográfica en el contexto del debate sobre la revolución mexicana a mediados del siglo xx.

El presente trabajo analiza Un niño en la Revolución Mexicana desde una perspectiva pragmática del texto, tratando de determinar su función social y comunicativa. En el acto de escribir, se argumenta, el tabasqueño trataba de superar el abismo, físico y emocional, que lo separaba de México. Quería mantener su identidad mexicana en el extranjero y presentarse como parte de la nación mexicana. ${ }^{16}$ En este proyecto identitario, sus textos autobiográficos juegan un papel sumamente importante. A fin de comunicar su pertenencia a la nación mexicana, Iduarte entretejió narrativamente y de manera variada su propia historia con la de su patria. Se sumergió, inevitablemente, en el mito revolucionario, que en aquel tiempo dominaba el discurso conmemorativo, ${ }^{17}$

${ }^{16}$ Con Benedict Anderson se entiende aquí la nación de una manera constructivista social, es decir, como una comunidad imaginada. Aunque es verdad que las naciones afirman que son entidades originales y naturales con largas tradiciones, realmente son el resultado de esfuerzos culturales considerablemente jóvenes. La nación se caracteriza por la imposibilidad de que todas sus partes se conozcan personalmente. Por eso la nación como comunidad de iguales tiene que ser siempre inventada, imaginada y construida. Véase Anderson, Comunidades imaginadas. Véase al respecto también Hobsbawm y Ranger (comps.), The Invention of Tradition.

17 Véase al respecto Benjamin, La Revolución; Córdova, "La mitología de la Revolución Mexicana"; Hale, "Los mitos políticos"; KNIGHT, "Myth of the Mexican Revolution"; Reséndiz García, "Del nacimiento y muerte". El discurso - en el sentido de Michel Foucault - "es el conjunto de reglas que en determinado momento histórico regula y determina las modalidades enunciativas, la formación de los conceptos, las estrategias posibles, y la formación de los objetos". López Bonilla y Pérez Fragoso, "Discurso", pp. 89-90. El "discurso conmemorativo" se refiere a las culturas conmemorativas (véase al respecto la nota 46 a pie de página de este ensayo). 
y tomó partido en el debate sobre la crisis y la muerte de la revolución mexicana. ${ }^{18}$

Este ensayo está dividido en tres partes. El primer apartado corresponde al instrumental metodológico en el que se sostiene el estudio. En esta sección se discuten en términos generales las posibilidades y los límites epistemológicos de las fuentes autobiográficas. Las narraciones autobiográficas ${ }^{19}$ cruzan con frecuencia las fronteras de los géneros textuales; oscilan entre historia y literatura y rehúsan cualquier definición simple. Por lo tanto, son textos problemáticos que reclaman un tratamiento específico y adecuado. En este estudio se consideran como construcciones narrativas de significado en un contexto comunicativo social y cultural específico, como era, por ejemplo, el discurso conmemorativo sobre la revolución mexicana. En el segundo apartado se examina la historia de la publicación de Un niño en la

18 Véase Ross (comp.), Is the Mexican Revolution Dead?

${ }^{19}$ Hay un debate en cuanto a la distinción entre los diferentes géneros autobiográficos como, por ejemplo, la autobiografía, el diario y las memorias. Los siguientes términos fueron propuestos para facilitar la distinción: egodocumento, testimonio (Selbstzengnis) y autobiografía. Véase al respecto KRUSENSTJERn, Was sind Selbstzengnisse. El problema con estos términos es que implican la idea de un sujeto consciente y autónomo que puede dejar un testimonio autentico de sí mismo. Por eso, empleo aquí el término "escritura autobiográfica" propuesto por Ulrich Breuer y Beatrice Sandberg, que abarca autobiografías, diarios y memorias, pero también poemas, dramas y novelas. No cuenta, explican los investigadores, con una "barrera [impermeable] entre ficción y realidad o entre literatura y no-literatura"; más bien reconoce el hecho de que haya penetraciones mutuas. Además, no supone "identidades fijas", sino que acentúa la fuerza identitaria de la escritura y de la lectura. BREuer y SANDberg, "Einleitung", p. 10. Por cuestiones de estilo, se usan aquí también los términos "narración autobiográfica" y "texto autobiográfico" en el mismo sentido. 
Revolución Mexicana. La historia de la publicación no sólo es importante para la interpretación, sino que también es significativa en sí misma, ya que muestra con claridad en qué medida los textos están imbricados en las relaciones políticas de poder. Con el tiempo, el texto se transformó formalmente de una novela autobiográfica en una autobiografía. La historia de la publicación de Un niño en la Revolución Mexicana refleja - reza el argumento aquí sostenido- los cambios políticos de poder en el Tabasco posrevolucionario. En el último apartado se ocupa de las memorias de infancia de Iduarte. Un niño en la Revolución Mexicana es una narración de conversión. Relata la transformación de Iduarte en hombre y su paralela transformación moral y política. El autor tabasqueño confesó en ella su pasado porfirista de "niño decente"; no obstante, al final se declaró a favor de la Revolución. El tabasqueño se convirtió de reaccionario en revolucionario.

\section{LA ESCRITURA AUTOBIOGRÁFICA}

COMO FORMA DE ACTUAR LINGÜÍSTICAMENTE

"La autobiografía mexicana existe", ${ }^{20}$ se vio obligado a constatar Richard D. Woods en un ensayo bibliográfico de 1994. Aunque existe un amplio corpus de narraciones autobiográficas, la mayoría de los textos es ignorada. La falta de interés en el mundo académico por la escritura autobiográfica no es una característica específica mexicana, sino que se puede confirmar para toda Hispanoamérica. Sylvia Molloy

20 Woods, "Mexican Autobiography", p. 750. Las traducciones de las citas inglesas de aquí en adelante son mías. 
explica al respecto que la autobiografía no sólo es una forma de escribir, sino también de leer: "Así, puede decirse que si bien hay y siempre ha habido autobiografías en Hispanoamérica, no siempre han sido leídas autobiográficamente”. ${ }^{21}$ Esa situación no ha cambiado mucho en los últimos años. Sorprendentemente, dice Ulrich Mücke, las narraciones autobiográficas siguen siendo raras veces tema de investigación entre los hispanoamericanistas. Recientemente, la ciencia literaria ha mostrado un interés creciente en cuanto a la escritura autobiográfica, en particular la del siglo xx.22 Por consiguiente, no es gratuito que en México la mayoría de los trabajos se concentre en las obras de escritores destacados. ${ }^{23}$ La obra autobiográfica mejor estudiada es, sin lugar a dudas, la de José Vasconcelos; ${ }^{24}$ además, se pueden mencionar las obras de Martín Luis Guzmán, Nellie Campobello y Elena Poniatowska. ${ }^{25}$

21 Molloy, Acto de presencia, p. 12.

22 Véase Mücke, “Autobiographisches Schreiben”, p. 204. Excepciones historiográficas son los trabajos publicados en el Jabrbuch für Geschichte Lateinamerikas/Anuario de Historia de América Latina, 47 (2010). Además se deben mencionar las siguientes obras: FERreIra de CASsone (comp.), Memoria y autobiografía en Iberoamérica; Aristizábal, Autodocumentos hispanoamericanos; MücKe y VelázQuez (comps.), Autobiografía del Perú.

23 Véase, por ejemplo, Ramos, Memorias y autobiografías, que presenta extractos de las obras autobiográficas de los siguientes autores famosos: sor Juana Inés de la Cruz, fray Servando Teresa de Mier, José Miguel Guridi y Alcocer, Guillermo Prieto, Federico Gamboa Iglesias, Victoriano Salado Álvarez, José Juan Tablada, Enrique González Martínez, José Vasconcelos y Jaime Torres Bodet.

24 Véase, por ejemplo, la publicación de Fell (comp.), José Vasconcelos.

25 Véase, por ejemplo, Jörgensen, The Writing of Elena Poniatowska, y Documents in Crisis. 
La historiografía mexicana no le ha prestado a la escritura autobiográfica la atención merecida. ${ }^{26}$ Varias podrían ser las causas que han dificultado su estudio historiográfico. Quisiera destacar particularmente dos. Por un lado, como explica Woods, la escritura autobiográfica no se ha cristalizado en un género literario en México. En general, se puede constatar cierta fluidez de las fronteras de género. Textos muy diferentes, entre ellos los autobiográficos, se juntan en México bajo la etiqueta "novela" - campo de investigación que evitan habitualmente los historiadores.$-{ }^{27}$ Por otro lado, bajo el paradigma económico y estructuralista en la historia social, las perspectivas subjetivas habían sido marginadas. Por mucho tiempo, como señala Luis Barrón, la investigación de los grandes procesos y estructuras sociales tenía prioridad. Esta situación cambió con el surgimiento de la nueva historia cultural a partir de los años ochenta y noventa del siglo pasado. Aunque también es cierto, como indica Barrón, que esta corriente historiográfica no ha logrado convertirse en un nuevo paradigma en las universidades mexicanas. La nueva historia cultural puso de nuevo énfasis en la subjetividad de los actores sociales. Sus enfoques son muy diversos. Se podrían nombrar, por ejemplo, los estudios de género, de las emociones o, también, de

${ }^{26}$ Una de las pocas excepciones es el trabajo de Zermeño Padilla, “Toribio Esquivel Obregón”. Significativamente, también se han analizado poco las biografías de personajes históricos.

${ }^{27}$ Véase Woods, "Mexican Autobiography within Mexican Literature", pp. 4 y 11, y, recientemente, Jörgensen, Documents in Crisis, pp. 5-8. Un buen ejemplo es la novela de la revolución mexicana, género muy problemático, que abarca textos ficticios, factuales e híbridos, como lo son las narraciones autobiográficas. Véase al respecto PaÚl ArRanz, "La novela de la Revolución Mexicana”. 
las memorias. ${ }^{28}$ Lo que une a los historiadores identificados con la nueva historia cultural es su preocupación por "la producción y reproducción de significados socialmente constituidos". ${ }^{29}$ Según ellos, el lenguaje es un medio omnipresente que no se puede trascender. Por eso, ponen en duda su capacidad de representación. De acuerdo con este razonamiento, los textos históricos no pueden dar acceso directo al pasado. Por el contrario, deben ser entendidos como elementos de procesos de comunicación históricos. De esa manera, el texto mismo se convierte en el centro de interés; se convierte en el hecho histórico sobre el cual se debe indagar. ${ }^{30}$ Las preguntas y las metodologías de la nueva historia cultural podrían dar nuevos impulsos al estudio de las narraciones autobiográficas.

Sin embargo, todavía prevalecen las lecturas tradicionales. En general - y no sólo en México - los textos autobiográficos suelen reducirse a meras fuentes de información. ${ }^{31}$ "Hasta hoy en día,” lamenta Dagmar Günther, “cartas, diarios, autobiografías $[\mathrm{y}]$ memorias pasan por realizaciones directas de la vida individual y colectiva en literatura". ${ }^{32}$ No se ha dimensionado su valor histórico. Un ejemplo característico del tratamiento historiográfico de fuentes autobiográficas es el texto Ocho mil kilómetros en campaña, del caudillo

28 Véase BARrón, Historias de la Revolución Mexicana, pp. 43-50 y 58.

29 VAN Young, "New Cultural History”, p. 214.

30 Véase Barrón, Historias de la Revolución Mexicana, pp. 43-50, y RAPHAEL, Geschichtswissenschaft, pp. 233-236.

31 MÜCKE, “Autobiographisches Schreiben”, p. 204.

32 GüNTHER, “And now for something completely different”, p. 27. Las traducciones de las citas alemanas de aquí en adelante son mías. 
revolucionario y presidente Álvaro Obregón..$^{33}$ Pedro Salmerón Sanginés ha podido mostrar recientemente que el texto es leído como una descripción auténtica de la contienda militar entre Obregón y Francisco Villa - no obstante su obvio cariz tendencioso-. Ello resultó, como señala Salmerón Sanginés, en una interpretación dudosa y parcial de los hechos que marcarían la revolución mexicana. ${ }^{34}$

La lectura de la obra autobiográfica de Iduarte igualmente está marcada por una postura problemática frente al texto. Desde el principio, las memorias de infancia de Iduarte fueron leídas como narración fidedigna y testimonio histórico. Para Mariano Picón Salas, por ejemplo, son "un gran testimonio mexicano". "La agudeza narrativa e interpretativa de Iduarte”, explica, "penetra donde no llegarán muchos estudios cargados de cifras [...] Es por indispensable adición obra histórica además de literaria". ${ }^{35}$ Luis Leal confirma en una reseña el valor del texto "como documento histórico". La narración es "de interés para los estudiantes de la historia de Tabasco y para los que se preocupan por elucidar ese gran movimiento social que cambió el rumbo de la historia de México, la Revolución mexicana". ${ }^{36}$ Ermilo Abreu Gómez afirma: "El libro de Andrés Iduarte - Un niño en la Revolución Mexicana - es todo verdad. No creo que contenga un adarme de mentira. Es un libro desnudo. En él se ven, de cuerpo entero, al escritor y al hombre. Ni finge, ni grita $[\ldots]$ Andrés Iduarte pudo poner al frente de su libro

\footnotetext{
33 Obregón, Ocho mil kilómetros.

${ }^{34}$ Véase con todo detalle Salmerón Sanginés, "Los historiadores y la guerra civil".

${ }^{35}$ Picón Salas, "Un gran testimonio mexicano", p. 227.

${ }^{36}$ Leal, "Iduarte y la Revolución Mexicana", p. 79.
} 
una frase de esta especie: aquí no se engaña a nadie”. ${ }^{37}$ Por eso, no sorprende que la lectura académica del texto no se diferencie. En su análisis de las actividades políticas de los estudiantes en el México de los años veinte, Gary D. Keller y Karen S. van Hooft recurren, por ejemplo, a las narraciones de Iduarte como "fuentes primarias de datos". ${ }^{38}$ Esta lectura confiada no ha tenido graves consecuencias interpretativas, sin embargo, es metodológicamente dudosa.

Hay que insistir, las narraciones autobiográficas no son representaciones objetivas de acontecimientos pasados; de ninguna manera pueden retratar fielmente el pasado. Tampoco, y en contra de lo que uno puede pensar, permiten el acceso inmediato al hombre, sus pensamientos o sentimientos íntimos. Los textos autobiográficos no reproducen simplemente el pasado, sino que lo (re)construyen e interpretan. Los autores les atribuyen posteriormente a los acontecimientos históricos contingentes un sentido inevitable y providencial que depende siempre de sus actuales "intereses y convicciones sociales, políticas, culturales y científicas". ${ }^{39}$ Las narraciones autobiográficas, indica Mücke, son elaboraciones retóricas muy complejas que están sometidas a estructuras específicas de poder, de percepción y de escritura. ${ }^{40}$ Por eso, Günther reclama un uso inteligente de las

37 Ermilo Abreu Gómez citado conforme a Morales, "En el centenario de Andrés Iduarte".

${ }^{38}$ Keller y Van Hooft, "Las actividades políticas", p. 212. Recientemente, Susanne K. Eineigel ha utilizado las memorias de Iduarte de la misma manera. Véase Eineigel, Distinction, Culture, and Politics, pp. 154, 156-157, 160-163.

${ }_{39}$ Heinze, "Autobiographie und zeitgeschichtliche Erfahrung”, p. 105.

40 Véase Mücke, "Introducción”, pp. 8-9. 
fuentes autobiográficas, que tome en consideración las estructuras narrativas en el trabajo interpretativo. La historiadora propone adoptar una perspectiva cultural frente al texto, que se ocupe de la "constitución de significado" y negocie "preguntas de forma, de código, de lengua $[y]$ de textualidad". ${ }^{41}$

Ahora bien, desde una perspectiva historiográfica, un análisis de las narraciones autobiográficas no debe quedarse sólo en el nivel narrativo. Por el contrario, los textos autobiográficos deben situarse plenamente en su contexto histórico. ${ }^{42}$ Volker Depkat explica, sosteniéndose en la pragmática lingüística ${ }^{43}$ impulsada por John L. Austin y John R. Searle, que se puede entenderlos como actos de habla con los cuales "el autor intenta establecer una relación comunicativa específica con un público imaginado en el acto de escribir". ${ }^{44}$ Ya que las narraciones autobiográficas formulan una oferta de comunicación a un lector implícito, los medios de expresión y exposición usados pueden dar pistas acerca de las intenciones comunicativas del autor. Así, indica Depkat, se pueden entender los texto autobiográficos "como actos de comunicación social en procesos de autoentendimiento" en un contexto social concreto. Consecuentemente, las narraciones autobiográficas pueden servir como

${ }^{41}$ Günther, “And now for something completely different”, p. 59.

${ }^{42}$ Véase DepкAт, "Plädoyer”, p. 213.

${ }^{43}$ La pragmática lingüística "estudia cómo los seres hablantes interpretamos enunciados en contexto. La pragmática estudia el lenguaje en función de la comunicación, lo que equivale a decir que se ocupa de la relación entre el lenguaje y el hablante". ReYes, La pragmática lingüistica, p. 17. ${ }^{44}$ Depкat, "Zum Stand und zu den Perspektiven der Autobigraphieforschung”, p. 177. 
"fuentes históricas que den informaciones sobre la historia de los procesos individuales y colectivos de producción de sentido". ${ }^{45}$

Las reflexiones metodológicas anteriores proporcionan los presupuestos para concebir las narraciones autobiográficas como elementos importantes de culturas conmemorativas (Erinnerungskulturen) ${ }^{46}$ Las culturas conmemorativas son modelaciones de la llamada memoria colectiva, que ocupa desde hace tiempo el interés teórico de las humanidades. El término de la memoria colectiva fue acuñado por Maurice Halbwachs,${ }^{47}$ quien ha llamado la atención sobre las condiciones sociales de las memorias. ${ }^{48}$ Es importante, como realza Jan Assamann al respecto, "no entender el discurso sobre la memoria colectiva de manera metafórica. Si bien es verdad que los colectivos no 'tienen' una memoria [propia], ellos determinan la memoria de sus miembros. Las memorias, aunque sean muy personales, surgen solamente por medio de la comunicación e interacción en un marco de grupos sociales". ${ }^{49}$

45 Véase Depкat, “Zum Stand und zu den Perspektiven der Autobigraphieforschung”, pp. 178-179.

46 El término cultura conmemorativa (Erinnerungskultur) describe "todas las formas posibles de la memoria consciente de acontecimientos, personajes y procesos históricos [...], ya sean de naturaleza estética, política o cognitiva. La noción abarca, pues [...] todos [...] los modos de representación de la historia, entre ellos el discurso historiográfico así como las memorias solamente 'privadas' [...]. Como portadores de esta cultura se manifiestan individuos, grupos sociales o incluso naciones y estados, parcialmente en consonancia, parcialmente en confrontación conflictiva”. CORNELIßEN, “Was heißt Erinnerungskultur?”, p. 555.

47 Véase Halbwachs, Das kollektive Gedächtnis.

48 Véase al detalle Assmann, Das kulturelle Gedächtnis, pp. 34-48.

49 Assmann, Das kulturelle Gedächtnis, p. 36. 
Según Claudia Ulbrich, Hans Medick y Angelika Schaser, las narraciones autobiográficas pueden ayudar a aclarar el proceso de transformación de las memorias que todavía permanece en la oscuridad, ya que, por un lado, se inscriben en las tradiciones y en los discursos contemporáneos y, por otro lado, proveen el material para memorias futuras; $;{ }^{50}$ en los textos autobiográficos se cruzan diferentes memorias individuales día y sincrónicamente y se transforman en narraciones que crean identidad(es) tanto para el presente como para el futuro. ${ }^{51}$ En las narraciones autobiográficas, la historia personal está frecuentemente entretejida con historias locales, regionales y nacionales - en el "yo" autobiográfico siempre está presente el "nosotros" colectivo-. De esa manera, los autores consiguen integrarse en los discursos conmemorativos y presentarse como parte de una historia comúnmente vivida y memorizada. Necesariamente, con sus textos los autores toman posición en un espacio de memoria cultural peleado.$^{52}$ Ello, explica Carsten Heinze, no sólo permite hacer transparentes "las formas autobiográficas heterogéneas de transformación de acontecimientos históricos [en memorias]", sino también "las líneas de conflicto en la historia contemporánea y en la cultura conmemorativa". ${ }^{53}$ En particular, la investigación de cambios históricos mediante textos autobiográficos es prometedora, juzga Depkat, ya que "un enfoque en el carácter de acción comunicativa de autobiografías permite a los historiadores reconstruir las configuraciones y reconfiguracio-

50 Véase Ulbrich, Medick y Schaser, Selbstzengnis und Person, pp. 13-14.

51 HeInze, “Autobiographie und zeitgeschichtliche Erfahrung”, pp. 101-105.

52 HeInze, “Autobiographieund zeitgeschichtliche Erfahrung”,pp. 115 y 119.

53 Heinze, “Autobiographie und zeitgeschichtliche Erfahrung”, p. 102. 
nes de sistemas de sentido colectivamente compartidos en el momento en el cual se vuelvan problemáticos". ${ }^{4}$

La revolución mexicana, que representa una cesura, tuvo una influencia profunda en el imaginario mexicano y transformó la memoria colectiva de manera persistente. El acontecimiento sobrepasó la capacidad de comprensión de la mayoría de los contemporáneos que, a su vez, intentaron superar la experiencia de crisis narrativamente. Se formaron diferentes memorias y narraciones que compitieron entre sí por el control interpretativo histórico político. ${ }^{55}$ Así, la Revolución llevó la producción autobiográfica a un nuevo auge histórico. Los años treinta del siglo xx comprenden "la época de oro de la autobiografía mexicana". ${ }^{56}$ Una de las muchas narraciones autobiográficas escritas en torno al suceso revolucionario fue Un niño en la Revolución Mexicana de Iduarte.

\section{TEXTUALIDAD Y REALIDAD:}

DE LA NOVELA AUTOBIOGRÁFICA A LA AUTOBIOGRAFÍA

Iduarte escribió sus memorias de infancia "en pleno fragor de la guerra de España". ${ }^{57}$ Anselmo Carretero, ensayista español y amigo de Iduarte, comenta al respecto: "Recuerdo perfectamente la noche en que Andrés fue a verme, en Valencia, al Ministerio de Estado. No le llevaba gestión concreta alguna y sólo el deseo de platicar conmigo [...]. Sacó

\footnotetext{
54 Depkat, "Zum Stand und zu den Perspektiven der Autobigraphieforschung”, p. 179.

55 Véase Benjamin, La Revolución, pp. 14, 20 y 31-78.

56 Woods, “Mexican Autobiography”, p. 752.

57 IDUARTE, “Nota a la presente edición” (1982), p. vii.
} 
de un cartapacio un montón de hojas con el escrito original de los primeros capítulos de 'Un niño en la Revolución mexicana' y me habló largamente de Tabasco". ${ }^{58} \mathrm{El}$ texto completo, sin embargo, fue publicado por primera vez sólo después de más de 14 años, en 1951, en la editorial Ruta.

Diferentes autores han intentado explicar este lapso curioso en la historia de la publicación del libro. Rodríguez Coronel, por ejemplo, insinúa, sin explicarse más, que a Iduarte, simplemente, no le era posible publicar sus memorias de infancia en España. ${ }^{59}$ No obstante, esta explicación no alcanza a convencer, ya que Iduarte sí publicó, después de todo, el primer capítulo de la narración en la revista Hora de España en diciembre de $1937 .{ }^{60}$

Víctor Díaz Arciniega propone, en cambio, lo siguiente: “Al conservar por casi 20 años inédito el manuscrito de 'Un niño en la Revolución Mexicana', Andrés Iduarte muestra que reserva para sí mismo su reconsideración sobre su educación y formación política, así como sus opiniones críticas sobre la historia reciente. Quizás”, considera Díaz Arciniega, "reconocía un valor privado que consideraba inconvenientemente hacer público o quizás pensaba que no era tiempo para exhibir su visión desencantada de su pasado. Este gesto de la reserva”, opina Díaz Arciniega, “es en sí mismo significativo en cuanto al contenido estrictamente personal, subjetivo e, incluso, íntimo de su dicho". ${ }^{61}$ Díaz Arciniega quiere ver en la curiosa discrepancia temporal entre redacción y publicación del texto, pues, una prueba

\footnotetext{
${ }^{58}$ Carretero, “Andrés Iduarte en España”, p. 34.

59 Véase Rodríguez Coronel, “Andrés Iduarte”, p. 113.

${ }^{60}$ Iduarte, "El mundo primero".

${ }^{61}$ Véase Díaz Arciniega, "La voz: el eco”, pp. 759-760.
} 
de su carácter privado, subjetivo e íntimo. Pero la supuesta intimidad del texto, como ya se ha explicado, es, teóricamente, muy dudosa. Es el resultado de una construcción retórica, que depende de normas y convenciones tanto literarias como sociales. Además, el texto en cuestión no se ocupa del estado psíquico de su protagonista, sino, más bien, de las condiciones históricas, políticas y sociales que han influido en la formación de Iduarte, es decir, de la revolución mexicana. Por lo tanto, el texto tampoco puede ser un "recurso terapéutico del autoconocimiento" o una sustitución de un "análisis psicoanalítico". ${ }^{62}$

Más plausible parece la idea de Díaz Arciniega de relacionar el retraso de la publicación con las convicciones políticas de Iduarte de entonces. Pero no es suficiente sólo identificar el problema con la "visión desencantada de su pasado", ${ }^{63}$ pues, la mayoría de las obras que aparecieron bajo la etiqueta de la novela de la revolución mexicana desarrollaron una perspectiva igualmente pesimista en cuanto a los acontecimientos revolucionarios y, sin embargo, fueron publicadas, en especial en la época de Lázaro Cárdenas del Río (19341940). ${ }^{64} \mathrm{El}$ problema aquí discutido no se puede resolver exclusivamente con base en el texto.

Las causas del retraso de la publicación de Un niño en la Revolución Mexicana se deben buscar en la situación política del Tabasco de los años veinte y treinta. El argumento aquí sostenido reza que Iduarte prefirió no publicar sus memorias por prudencia política, ya que sus parientes

${ }_{62}$ Díaz Arciniega, "La voz: el eco", pp. 758 y 762.

${ }^{63}$ Díaz Arciniega, "La voz: el eco", p. 759.

${ }^{64}$ Véase Bruce-NovoA, "La novela de la Revolución Mexicana”. 
estaban íntimamente envueltos en los conflictos políticos de entonces.

Entre 1922 y 1935 dominaba la política en Tabasco el entonces protegido de los presidentes Obregón y Plutarco Elías Calles: Tomás Garrido Canabal, personaje que hasta hoy en día es muy controvertido. ${ }^{65}$ No por casualidad, la época mencionada fue bautizada por Carlos Martínez Assad "El tiempo de Garrido". ${ }^{66}$ El anticlericalismo radical y las campañas en contra del consumo de alcohol lo hicieron famoso más allá de Tabasco. Su imagen varía, explica Stan Ridgeway, entre socialista progresivo, déspota que quería destruir la Iglesia católica y dictador corrupto con una disposición al fascismo. ${ }^{67} \mathrm{Su}$ balance político es, por consiguiente, muy ambivalente. Por un lado, dejó construir un sinnúmero de nuevas escuelas, introdujo el sufragio femenino, siendo uno de los primeros gobernadores en hacerlo en la República mexicana, y amplió las redes de comunicación y transporte. Impulsó igualmente con vehemencia el proceso de la secularización. Además, durante su gobierno, los grupos sociales marginados adquirieron mayor peso en la política. Por otro lado, su gestión fue marcada por la arbitrariedad y la violencia. En el nombre de la Revolución, los derechos individuales fueron con frecuencia violados. ${ }^{68}$

${ }^{65}$ Véase Martínez Assad, El laboratorio de la Revolución. Kristin A. Harper cuenta que su ponencia sobre las reformas políticas provechosas de Garrido en el First Annual Congress of Tabasco Historians en 2001 ha causado un debate emocional entre partidarios y enemigos de Garrido. Véase Harper, “Tomás Garrido Canabal”, p. 109.

${ }^{66}$ Véase Martínez Assad, Breve historia de Tabasco, pp. 159-221.

${ }^{67}$ Véase Ridgeway, "Monoculture, Monopoly, and the Mexican Revolution”, pp. 143-144.

${ }^{68}$ Véase Harper, “Tomás Garrido Canabal”, p. 110. 
Particularmente, la organización juvenil de los llamados "camisas rojas" y su brazo paramilitar provocaron miedo y espanto entre la oposición y los católicos. ${ }^{69}$ De ahí que Kristin A. Harper concluya: "Aunque [es] exagerado caracterizar el Tabasco de la era de Garrido como un feudo sin ley, una disposición a tratar los principios constitucionales sin cuidado fue una característica bastante pronunciada del régimen de Garrido" ${ }^{70}$

Iduarte conocía personalmente a Garrido porque éste había sido alumno de su padre en el Instituto Juárez de Tabasco. Además, Iduarte obtuvo de parte del general tabasqueño una renovación de una beca, la que aceptó sólo a regañadientes, porque pertenecía en aquel tiempo a la oposición política tabasqueña ${ }^{71}$ - sobre todo por su primo mayor, Rodulfo Brito Foucher, que fue uno de los enemigos políticos más destacados de Garrido-.${ }^{72}$ Cuando era estudiante universitario, Iduarte y sus compañeros de la Unión de Estudiantes Tabasqueños criticaron en el periódico Tabasco Nuevo tanto la persona como la política de Garrido - “en nombre de la misma Revolución que él invocaba [lo] combatíamos con la pluma, como legítimos tabasqueños y jóvenes de verdad, a sangre y fuego". ${ }^{73}$ "El sultán rojo",

69 Véase Martínez Assad, El laboratorio de la Revolución, pp. 174-178, y Martínez Assad, Breve historia de Tabasco, pp. 205-206.

70 Harper, “Tomás Garrido Canabal”, pp. 111-112.

71 Aún después de muchos años Iduarte dijo con orgullo: "Fui enemigo ardiente de Garrido, y tengo que decirlo con satisfacción, pues lo fui abierta, leal y desinteresadamente: cuanto pensé lo dije, cuanto dije lo sostuve”. IDUARTE, El mundo sonriente, p. 36.

72 Véase Contreras PÉrez, Rodulfo Brito Foucher (1899-1970) y Urías Horcasitas, “Autoritarismo y violencia”.

73 Iduarte, “Don Pedro de Alba”, p. 6. 
un artículo provocador, da un buen ejemplo de esa actitud combativa. En él, Iduarte calificó a Garrido como déspota oriental. ${ }^{74}$

Cuando en junio de 1935 se dio la ruptura entre Cárdenas y Calles, los opositores políticos de Garrido vieron la posibilidad de "reconquistar" Tabasco en una "expedición punitiva”, como explica Martínez Assad. Para las preparaciones necesarias, los enemigos de Garrido se juntaron en la casa de Rodulfo Brito el 13 de julio. La Secretaría de Comunicaciones y Obras Públicas les dio la protección política por orden del general Francisco J. Múgica. El 15 de julio del mismo año, los expedicionarios y los partidarios de Garrido chocaron en Villahermosa. Varias personas fueron asesinadas en este encuentro violento - entre las cuales estaba también Manuel Brito Foucher, el hermano menor de Brito y primo de Iduarte. ${ }^{75}$ " $[\mathrm{No}]$ puedo olvidar que la muerte de mi casi hermano Manuel Brito Foucher, el menor y, por esto, el más tiernamente querido de mis primos, cercenado en Villahermosa por las ametralladoras de los 'camisas rojas', en 1935, me llenó de pena y de horror, cuando recibí, en España, la tremenda noticia", ${ }^{76}$ recuerda Iduarte. Por consecuencia, había muchas manifestaciones en la ciudad de México en contra de Garrido, a quien se acusó por el derrame de sangre. En particular los estudiantes se solidarizaron con las víctimas. ${ }^{77}$ El presidente Cárdenas se aprovechó

\footnotetext{
74 IDUARTE, "El sultán rojo".

${ }^{75}$ Véanse Martínez Assad, El laboratorio de la Revolución, pp. 230-231 y Breve historia de Tabasco, pp. 207-208.

${ }^{76}$ IDUARTE, El mundo sonriente, pp. 34-35.

77 Véanse Martínez Assad, El laboratorio de la Revolución, pp. 231-232 y Breve historia de Tabasco, p. 208. Aún años después, se conmemoraba
} 
políticamente de la situación tensa y forzó a Garrido, el ya molesto partidario de Calles, en una misión agraria al "exilio voluntario" en Costa Rica. ${ }^{78}$ Pero también Rodulfo Brito, que había soñado con el cargo de gobernador de Tabasco, tuvo que exilarse después de que había igualmente roto con Cárdenas. En 1936 viajó, pues, a Berlín, ya nacionalsocialista. ${ }^{79}$

Garrido dejó en Tabasco un vacío de poder problemático, como explica Martínez Assad, lo que no dejó que el estado se apaciguara de inmediato. La sociedad estaba dividida. Los partidarios de Garrido todavía ocuparon cargos importantes tanto en el aparato político como en el militar e impidieron efectivamente la contratación de personas identificadas con la oposición. Los "camisas rojas" siguieron activos a pesar de la ausencia de su patrón. Además, Garrido mismo dispuso aún de contactos políticos y de propiedad intacta en

a los muertos. En La Reacción (?), semanario de la derecha política mexicana, Nemesio García Naranjo reprodujo un discurso que había pronunciado ante las tumbas de los estudiantes Manuel Brito Foucher, César Pedrero y G. Juárez Merino: "Con profunda emoción veo la juventud universitaria de México acercarse a estas tres tumbas, convertidas en altares, para conmemorar la proeza más limpia y noble de nuestro país, en últimos tiempos. Todo fué [sic] decoro y pulcritud en la cruzada heroica que se organizó para ir a libertar el Estado de Tabasco de un despotismo hermético que amenazaba extenderse y herir toda la República. Aquella expedición fué [sic] inspirada en un ideal altísimo, fortalecida por una doctrina moral irreprochable, sostenida por un valor a toda prueba y consagrada por la sangre generosa del martirio [...].” Nemesio García Naranjo, "Una proeza limpia”, La Reacción (?), 3:28 (3ª) (28 jul. 1941), pp. 4-8, p. 4.

78 Véanse Martínez Assad, El laboratorio de la Revolución, p. 232 y Breve historia de Tabasco, pp. 208-209.

79 Véase Contreras Pérez, "Rodulfo Brito Foucher: 'La Revolución era ya un pudridero moral”", pp. 164 y 167. 
Tabasco, que se trató de disolver tan sólo a principios de los años cuarenta. ${ }^{80}$

Es más que probable que Iduarte haya tomado en consideración la situación incierta y políticamente tensa en cuanto a la publicación de Un niño en la Revolución Mexicana, ya que sus memorias de infancia no sólo tratan la historia controvertida de la Revolución en Tabasco, sino asimismo mencionan a varias personas entonces políticamente activas $-\mathrm{y}$ no siempre de manera lisonjera - ${ }^{81}$ Además, Iduarte presenta a los suyos como enemigos vehementes de la Revolución y partidarios apasionados de Porfirio Díaz. En caso de duda, tal descripción podría comprometer a los parientes de Iduarte, cuanto más que, en 1938, su primo Brito fue considerado como posible candidato de la oposición a la presidencia de la República. ${ }^{82}$ Aunque es cierto que no se puede saber con absoluta certeza que Iduarte prefiriera aplazar la publicación de su narración autobiográfica por prudencia política, esa explicación tiene mucha plausibilidad ante las trágicas complicaciones familiares por los acontecimientos políticos antes descritos. En 1938, Iduarte, simplemente, no podía saber cómo se desarrollarían las condiciones políticas en Tabasco. La posibilidad de un regreso de Garrido al poder, aunque fuera mínima, no se podría excluir con seguridad. Tal giro de acontecimientos, probablemente no hubiera sido favorable para la familia de

${ }^{80}$ Véase Martínez Assad, Breve historia de Tabasco, pp. 222-224 y también 231-234.

${ }^{81}$ Véase, por ejemplo, la descripción despectiva de Tomás Garrido Canabal. IDUARTE, Un niño en la Revolución Mexicana, pp. 97-98.

82 Véase Contreras Pérez, "Rodulfo Brito Foucher: 'La Revolución era ya un pudridero moral'”, pp. 165-166. 
Iduarte ya que, indirectamente, era responsable del exilio de Garrido. La publicación temprana del libro le hubiera sido un mal servicio a la familia de Iduarte, que todavía disponía de propiedades en el estado de Tabasco y de las cuales, sobre todo Brito, dependía en su nuevo exilio en Washington. ${ }^{83}$ Con la decisión de aplazar la publicación, Iduarte podía evitar tal riesgo.

Esta explicación cuadra bien con el hecho de que Iduarte varió en las primeras tres ediciones de Un niño en la Revolución Mexicana tanto los nombres propios de sus parientes como el de Garrido: los Foucher se llaman Gramont y Garrido lleva el nombre de "Dimas Gamarra, el rojo". Posteriormente, Iduarte declaró que les había querido dar "carácter de novela" ${ }^{44}$ a sus memorias de infancia. Pero hay que preguntarse ¿por qué tenía esta intención? Iduarte no explica más. Todo parece indicar que quería evitar que se leyera su narración autobiográfica como texto referencial. En mi opinión, no lo hizo por cuestiones sólo literarias, sino, como se ha dicho, por prudencia política y familiar, ${ }^{85}$ ya que en contra de su declaración, de haber procedido así con casi todas las personas que aparecían en el texto, ${ }^{86}$ los

${ }^{83}$ Brito tuvo que exilarse de nuevo, ya que había denuncias de que él apoyaba la propaganda fascista. Esas acusaciones les parecían a muchos muy probables, por su visita anterior a Alemania. Esta vez, Brito se fue a Washington, D.C., en donde permaneció con su familia hasta el fin del gobierno de Cárdenas. Véase Contreras Pérez, "Rodulfo Brito Foucher: 'La Revolución era ya un pudridero moral”", pp. 166-167.

${ }^{84}$ IDUARTE, "Nota a la presente edición” (1982).

${ }^{85}$ Rodríguez Coronel, “Andrés Iduarte”, p. 110, en cambio, opina que la ficcionalización mediante el cambio de nombres es una estrategia narrativa de Iduarte con el fin de otorgar al texto un carácter universal. ${ }^{86}$ Véase IDUARTE, El mundo sonriente, p. 34. 
cambios de nombre se limitan exclusivamente a su familia y Garrido. Otras personas sí son llamadas con sus nombres reales. Iduarte cuenta, por ejemplo, que muchas veces se sentaba, como niño pequeño, en las rodillas de Rafael Martínez de Escobar, Francisco J. Santamaría, Manuel Bartlett - todos serían después importantes figuras políticas-; el primero fue asesinado en la masacre de Huitzilac, los últimos dos conseguirían la gubernatura de Tabasco. ${ }^{87} \mathrm{No}$ obstante, con el tiempo, los motivos para tal precaución desaparecieron: Garrido murió el 8 de abril de 1943 en Los Ángeles, y en Tabasco aparecieron las señales de una "nueva era". 88

Un niño en la Revolución Mexicana refleja los cambios en el ámbito político de manera curiosa: con los años, su carácter referencial histórico se marcó paulatinamente y se transformó de una novela autobiográfica en una autobiografía auténtica.

Philippe Lejeune llama novela autobiográfica a "todos los textos de ficción en los cuales el lector puede tener razones para sospechar, a partir de parecidos que cree percibir, que se da una identidad entre el autor y el personaje, mientras que el autor ha preferido negar esa identidad, o, al menos, no afirmarla”. Por el contrario, una autobiografía auténtica, insiste Lejeune, requiere una identidad de nombre entre autor, narrador y protagonista sin ambigüedades. La

${ }^{87}$ Véase Iddarte, Un niño en la Revolución Mexicana, p. 38. Para otros ejemplos véanse pp. 88, 96 y 99. Igualmente, los adversarios políticos, Carlos Greene y Luis Felipe Domínguez, llevan su nombre real. Véase, por ejemplo, IDUARTE, Un niño en la Revolución Mexicana, p. 95.

${ }_{88}$ Véase Martínez Assad, Breve historia de Tabasco, pp. 222-243, en particular, pp. 231-243. 
afirmación de esta identidad se ratifica en un 'pacto autobiográfico' entre autor y lector. ${ }^{89}$ Este contrato de lectura garantiza al lector la verdad de los enunciados. En este contexto, los llamados paratextos (el título, el prólogo y el epílogo, el texto de portada, etc.) juegan un papel sumamente importante, ${ }^{90}$ ya que orientan al lector y dirigen su lectura; le sugieren firmar o no el "pacto autobiográfico".

En España, Iduarte publicó el primer capítulo de su autobiografía aún bajo el título de El mundo primero. Capitulo de la novela Tabasco (un niño en la Revolución Mexicana). ${ }^{91}$ El lector tiene que presuponer que se trata de un texto novelístico que forma parte de una novela autobiográfica; es un texto más ficticio que factual. Pero, 14 años más tarde, en la primera publicación completa de la narración, todo indicio de que se tratara de un texto ficticio había desaparecido del título. Aquí se dice lacónicamente: "Un niño en la Revolución Mexicana por Andrés Iduarte". Faltan un prólogo o una introducción que orienten al lector. Solamente el texto de portada sirve para tal fin. No obstante, éste sugiere una narración autobiográfica auténtica. El texto de portada promete al lector explicaciones en cuanto al desarrollo económico y social de México y resalta el carácter factual del escrito, alegando "datos esenciales" e “informaciones [...] de primera mano" para "precisar la significación exacta, actual y futura, de los asuntos palpitantes del país". ${ }^{92}$ El lector tiene que asumir que se trata de

\footnotetext{
${ }^{89}$ Véase Lejeune, El pacto autobiográfico. Para la cita véase p. 63.

90 Véase al detalle Heinze, "Der paratextuelle Aufbau der Autobiographie".

${ }^{91}$ IDUARTE, "El mundo primero".

92 Texto de portada de Iduarte, Un niño en la Revolución Mexicana.
} 
una narración factual e histórica de la revolución mexicana. El diseño sobrio y neutral del libro apoya esta impresión. El pacto autobiográfico, sin embargo, no se puede llevar a cabo por las dudas respecto de la identidad del nombre. ${ }^{93}$ Las dudas acerca de la identidad entre autor, narrador y protagonista se desvanecieron por primera vez en la traducción del libro al inglés en 1971. ${ }^{94}$ Aquí los Foucher, de hecho, se llaman por primera vez Foucher — sólo Garrido se queda con su seudónimo de "Dimas, the Red". La versión definitiva del texto se encuentra, según el mismo Iduarte, en la edición de sus obras completas publicadas en 1982. ${ }^{95}$ Aquí todos los nombres cambiados ya están, por fin, corregidos. La oferta del pacto autobiográfico se puede constatar aquí, sin lugar a dudas. El texto representa ahora sí una autobiografía auténtica en el sentido de Lejeune. La autenticidad del texto está subrayada, además, por varias fotografías que Iduarte incorporó de él mismo y de sus familiares. ${ }^{96}$ A pesar

${ }^{93}$ Dudas en cuanto al pacto autobiográfico surgen por los cambios de los nombres familiares. Ahora bien, para esto el lector tiene que saber que el apellido materno de Iduarte no es Gramont sino Foucher. No obstante, en la portada sólo aparece el apellido paterno: Iduarte. Sin indagación ninguna, no se puede confirmar ni descartar el pacto autobiográfico. 94 Iduarte, Child of the Mexican Revolution.

${ }^{95}$ IDUARTE (comp.), Un niño en la Revolución Mexicana.

96 Véase Idduarte, "Nota a la presente edición" (1982), p. vii. Las fotografías se encuentran a la mitad del libro; no son parte de la paginación. Con el motivo del centenario de la revolución mexicana el texto fue publicado de nuevo en 2010. Curiosamente, por error de cita, se publicó la versión de 1951. Arturo Azuela escribe en la introducción lo siguiente: "Novela escrita en 1937, entre Madrid y Barcelona, en los avatares de la guerra civil, 'en una hora revolucionaria', 'Un niño en la Revolución Mexicana' fue designado por la crítica como un texto autobiográfico. El autor nos dice que 'en las tres primeras ediciones varié los nombres de sus 
de la corrección de los nombres y unos cambios marginales, el texto se conservó íntegramente. ${ }^{97}$ Ello apoya la hipótesis aquí planteada de que no fueron causas literarias sino, más bien, factores externos al texto los que condicionaron los cambios realizados. Parece que al final, en un contexto histórico diferente, Iduarte ya no consideró necesario el embozo de las figuras y estuvo dispuesto a asumir, también formalmente, la "responsabilidad intencional y ética" 98 su historia de vida.

\section{UNA CONFESIÓN MEXICANA:}

DE REACCIONARIO A REVOLUCIONARIO

En Un niño en la Revolución Mexicana Iduarte presenta sus memorias de infancia. Aunque sea cierto que la Guerra Civil española era el horizonte de Andrés Iduarte cuando escribía Un niño en la Revolución Mexicana, como afirma Rodríguez Coronel, ${ }^{99}$ no debe ser el fondo ante el cual se lea el texto, ya que Iduarte publicó el libro entero por primera

personajes y le di carácter de novela’. Será en la edición en inglés, de 1971, cuando aparecerán algunos nombres auténticos, y en la edición definitiva - la de 1951 [sic] - "están ya todos los nombres y asoman en fotografía los familiares que forman mi mundo primero". IDUARTE, Un niño en la Revolución Mexicana (2010), p. 12. La editorial confirma crédulamente: "Es esa la versión que publicamos ahora", pero la versión definitiva no es la del año 1951, sino la de 1982.

${ }^{97}$ Una excepción la representa el capítulo "Prosapia". En él Iduarte esboza el árbol genealógico. Iduarte cambió obviamente unos párrafos. No obstante, el contenido sigue siendo fundamentalmente el mismo. Véase IdUARTe, Un niño en la Revolución Mexicana, pp. 29-38, e IdUARTe (comp.), 'Un niño en la Revolución Mexicana', pp. 21-29.

${ }_{98}$ Heinze, "Autobiographie und zeitgeschichtliche Erfahrung”, p. 95.

99 Véase Rodríguez Coronel, “Andrés Iduarte”, pp. 107-108 y 110. 
vez en México en 1951, 14 años después de su redacción. ${ }^{100}$ Mediante la publicación del texto efectuó un acto de habla y participó en un debate muy controvertido: el debate conmemorativo sobre la revolución mexicana, dominado por el mito revolucionario.

“'La Revolución”, dice Thomas Benjamin, “fue un producto de la memoria colectiva, de la creación de mitos y de la escritura de historia”. ${ }^{101}$ En los años veinte y treinta del siglo xx, la Revolución se transformó paulatinamente en un mito político que se fundió en la tradición liberal mexicana. Fue el equivalente discursivo del proceso de la conciliación política, sin duda, un proceso difícil y contradictorio. ${ }^{102} \mathrm{El}$ mito revolucionario ganó en legitimidad sobre todo por la persona y la política de Lázaro Cárdenas. "Probablemente”, reflexiona Reséndiz García, "la Revolución Mexicana no

100 El hecho de que Iduarte haya decidido narrar su vida por medio de la revolución mexicana es significativo en sí mismo, cuanto más que se trata de memorias de infancia, ya que en el siglo xIX se solía evitar la petite histoire por cuestiones políticas e identitarias. Véase Molloy, Acto de presencia, pp. 113-117. Un niño en la Revolución Mexicana no es el único ejemplo. Al contrario, el texto formó parte de una producción creciente de memorias de infancia con referencia explícita a la Revolución a mediados del siglo xx. Véase, por ejemplo, Garizurieta, Recuerdos; NúÑez Guzmán, Mi infancia; CÁrdenas, Mi padre y yo, y Beteta, Jarano. Se podría deducir que la Revolución se volvió referencia indispensable de la escritura autobiográfica mexicana de aquella época. Hasta qué punto esta hipótesis es válida, se tendría que comprobar mediante otros estudios en el futuro.

101 Benjamin, La Revolución, p. 19.

102 Véase Benjamin, La Revolución, p. 22 y Knight, "The Myth of the Mexican Revolution”, pp. 237-238 y 255. Knight distingue tres fases de desarrollo del mito revolucionario: la fase formativa (1920-1940), la fase clásica (1940-1982) y la fase posclásica (1982-presente). Aquí se sigue la periodización de Knight. 
hubiese adquirido su carácter de mito fundacional sin las reformas sociales cardenistas". ${ }^{103}$ Entre 1940 y 1982, el mito revolucionario, señala Alan Knight, "se cristalizaba". ${ }^{104}$ En aquel entonces, ya se había impuesto la idea de que la Revolución fue una revolución autentica, social y popular; un proceso singular, homogéneo y continuo; la última etapa, después de la Independencia y la Reforma, en la larga lucha del pueblo mexicano por la libertad y la justicia. ${ }^{105}$ Pero no sólo fue construida e historizada, sino también cosificada: "La Revolución cosificada fue concreta, independiente y autónoma, algo fuera, por encima y casi más allá de la acción humana [...]. Adquirió una solidez en los textos impresos que nunca ha tenido en realidad". ${ }^{106}$ De manera maniquea, se interpretaba la historia nacional como un conflicto de fuerzas antagónicas. A la Revolución se contraponía la Reacción, y el régimen callista se declaró protector del proceso revolucionario en contra de las fuerzas reaccionarias. No obstante, la función legitimadora del mito revolucionario se transformaba con el tiempo en una función crítica. ${ }^{107}$ En los conflictos políticos, ya no sólo el régimen, sino también sus adversarios, podían remitirse al mito revolucionario. La Revolución, explica Knight, "proporcionó un tipo de 'public transcript', ampliamente aprobado, aunque sin unanimidad, frente al cual los ciudadanos - a menudo

103 Reséndiz García, “Del nacimiento y muerte del mito político”, p. 150.

${ }^{104}$ Véase Knight, “The Myth of the Mexican Revolution”, p. 260.

105 Véase Benjamin, La Revolución, pp. 22, 42-43, 137 y 139.

106 Benjamin, La Revolución, pp. 44-45.

107 Véase Benjamin, La Revolución, pp. 44-47, 73-74, 76-77 y 158. 
ciudadanos críticos y descontentos - juzgaban el régimen, a sus secuaces y sus actos". ${ }^{108}$

Cuando se publicó Un niño en la Revolución Mexicana, el debate conmemorativo sobre la revolución mexicana estaba en pleno desarrollo. Vasconcelos ya había publicado sus memorias, que habían provocado un eco autobiográfico múltiple. ${ }^{109}$ En vista de la imperante desigualdad social y la extendida corrupción, importantes intelectuales, entre ellos Daniel Cosío Villegas y Jesús Silva Herzog, constataron una crisis moral y política en México y declararon públicamente la muerte de la Revolución. ${ }^{110}$

Iduarte tomó partido en esta discusión: "La Revolución triunfó y está viva", ${ }^{111}$ insistió. Asimismo, advirtió del peligro de la contrarrevolución. Por lo tanto, la promoción del escepticismo y de la resignación por parte de varios intelectuales destacados fue, en su opinión, poco más que irresponsable y antipatriótico. Aunque concedió errores y equívocos en el movimiento revolucionario, opinaba que tal actitud sólo jugaría en favor de las "fuerzas reaccionarias". Iduarte privó a toda crítica fundamental su legitimidad. En cambio, aconsejó que lo que se tenía que hacer era: "avanzar en lo bueno y apartar lo malo, juntar el programa material más ambicioso con el más escrupuloso celo moral, hermanar

108 Knight, “The Myth of the Mexican Revolution”, p. 262. Véase también p. 265. Durante las últimas décadas del siglo xx, el mito revolucionario se emancipaba del régimen priista. Es notable que aún goza de legitimidad. Dice Arnaldo Córdova al respecto: "Nuestra mitológica Revolución Mexicana, a la que tantas veces hemos 'liquidado', está aquí de nuevo". CóRdova, "La mitología de la Revolución Mexicana”, p. 32. 109 Véase Díaz Arciniega, "La voz: el eco".

110 Véase Ross (comp.), Is the Mexican Revolution Dead?

111 Iduarte, "El legado de la Revolución”, p. 111. 
la mayor justicia social posible con la más pura dignidad y el más alto decoro internacional. Es el deber de todos los mexicanos que creen en su patria y en su Revolución". ${ }^{112}$

$\mathrm{Al}$ escribir, Iduarte entretejía su propio destino y el de su generación con la revolución mexicana. De esa manera el autor, viviendo en el extranjero, se aseguraba de su mexicanidad y comunicaba su pertenencia a la nación mexicana. Con pathos declaró: "Pensamos como pensamos [...] porque en México nacimos y en nuestra Revolución nos criamos". ${ }^{113}$ De este hecho, dice, resulta la responsabilidad de contar la Revolución: "Quizá los que más lo sentimos somos los que entre sus llamas comenzamos la vida; [...] quizá su majestad llegó primero a los que nacimos en el incendio, y vivimos la juventud en su rescoldo; $y$, sin duda, quienes más tenemos que contarla y cantarla, somos nosotros. No la hicimos: ella nos hizo". ${ }^{114}$

Iduarte cumplió de manera ejemplar con esta obligación que se impuso también a sí mismo. Al escribir, se acordó melancólicamente de su niñez y juventud en el México revolucionario. Pero no escribió su libro para imponer su interpretación de la historia mexicana. "El que cuenta desde lejos no lo hace para cambiar la historia del mundo, ni de su México", explica, "sino para lustrar los valores permanentes que su México le dio, y para recrearlos en los corazones memoriosos como el suyo". ${ }^{115}$ Puesto que, "por ese pedacito, nomás, a México pertenecemos, y a él nos aferramos". ${ }^{116}$

\footnotetext{
112 Iduarte, "El legado de la Revolución”, p. 116.

113 Iduarte, "Nuestra Revolución Mexicana”, p. 103.

114 IDUARTE, "El 20 de noviembre", p. 95.

115 Iduarte, "Don Pedro de Alba", p. 24.

116 Iduarte, "Don Pedro de Alba”, p. 24.
} 
Iduarte era consciente de la subjetividad y limitación de su narración autobiográfica: "Uno de tantos testimonios de mi tiempo es el mío. No es más, y sé bien que no es más que lo que es". ${ }^{117}$ Sin embargo, insistió en la necesidad de dejar un testimonio. Aunque concede que "sombras seremos en unos cuantos años más y algunos ya lo son. Pero ese que repaso es nuestro mundo, y quienes lo vivimos de los pies a la cabeza debemos dejar un testimonio". ${ }^{118}$ Según Iduarte, Vasconcelos mismo lo apoyó en su intención de contar su vida y lo exhortó: "Escriba, escriba y publique ahora, o escriba ahora y publique después [...] Deje su testimonio". ${ }^{119}$

En la interpretación de Un niño en la Revolución Mexicana, no se trata de reconstruir la infancia de Iduarte y comprobar históricamente su narración. "La autobiografía no depende de los sucesos sino de la 'articulación' de esos sucesos, almacenados en la memoria y reproducidos mediante el recuerdo y su verbalización." 120 Se trata de entender el texto como una construcción narrativa de sentido. En 16 capítulos, Iduarte narra la historia de su transformación en hombre y de su paralela depuración moral y política. El autor recurre a un tipo de narración autobiográfica con mucha tradición que fue acuñado por las Confesiones de Agustín de Hipona: ${ }^{121}$ la narración de conversión. Iduarte se ve confrontado con la verdad exigente de la revolución mexicana: "Había una verdad establecida, y era la Revolución”. ${ }^{122}$ Esta verdad le

\footnotetext{
117 IdUarte, “Don Pedro de Alba”, p. 35.

118 Iduarte, “Don Pedro de Alba”, p. 24.

119 IDUARTe, "Don Pedro de Alba”, p. 35.

120 Molloy, Acto de presencia, p. 16.

121 Agustín de Hipona, Confesiones. Véase al respecto Wagner-EgelHAAF, Autobiographie, pp. 112-118.

122 IDUARTE, Un niño en la Revolución Mexicana, p. 166.
} 
exige a Iduarte su confesión y lo obliga a trabajar su vida autobiográficamente. Iduarte cuenta cómo se convirtió de reaccionario en revolucionario y justifica su antiguo reaccionarismo político que ante la realidad revolucionaria le parece incomprensible y erróneo.

La revolución mexicana es tanto punto de partida de la narración como el fin y el fondo del texto. Desde el principio, Iduarte relaciona su propia vida con la Revolución: "Lo que para mi vida [...] es importante", declara, "es que nací en 1907, cuando ya México se desperezaba políticamente, cuatro años antes de que se derrumbara el gobierno del general Porfirio Díaz. Me iba a tocar una infancia roja”. ${ }^{123}$ No obstante, esto lo impide el estatus social de sus familiares maternos, "que enclavaría nuestra infancia dentro de la contrarrevolución”. ${ }^{124}$

Iduarte dota la relación tensa entre revolución y contrarrevolución, entre revolución y reacción con el problema de la desigualdad social. De manera significativa, su familia se divide en ricos y pobres. A diferencia de sus parientes maternos que disponen de una fortuna considerable e influencia política, la familia paterna pertenece a las más pobres de todo Tabasco. Iduarte se sitúa a sí mismo y a su familia socialmente en el medio. Sin embargo, no puede sustraerse del "ambiente feudal" 125 del lado materno - con todas sus implicaciones políticas y sociales-. En diferentes escenas golpea el "niño decente" a los sirvientes de la casa y confiesa al lector: "Yo era de mal genio. Alzaba la mano con

${ }^{123}$ IdUarte, Un niño en la Revolución Mexicana, p. 7.

${ }^{124}$ IdUarte, Un niño en la Revolución Mexicana, p. 30.

125 IdUarte, Un niño en la Revolución Mexicana, p. 27. 
facilidad". ${ }^{126}$ Incluso deja que uno de sus amigos le orine a un criado en la cara. Significativamente, estas escenas están reunidas bajo el título "Preludios revolucionarios". Representan la desigualdad social en la sociedad porfiriana, que Iduarte identifica con la causa del alzamiento popular. No es por casualidad que una persona sin nombre comente los abusos del niño de la siguiente manera: "Todo eso iba a acabar cuando viniese la Revolución”. ${ }^{127}$

Con todo, Iduarte realza desde el principio, sutilmente, su "conexión con el pueblo". ${ }^{128}$ No es nada gratuito que mencione que cumple años el $1^{\circ}$ de mayo, el "Día de los Trabajadores", ${ }^{129}$ y que es el nieto de un carpintero. Incluso en la privilegiada familia materna existe una tradición "del entendimiento callado de la causa popular y de la posible dedicación a su defensa" ${ }^{130}$ El discurso del "pueblo" ya se había establecido como convención social, e Iduarte se aprovechó de ello narrativamente cuando escribió sus memorias. $\mathrm{Al}$ elaborarse su vinculación con el pueblo, Iduarte subraya su inclinación revolucionaria. El siguiente cambio de su conciencia política, deja saber al lector, es coherente e inevitable.

El cambio de la conciencia política de Iduarte se funda en una transformación moral. La Revolución obliga a la familia de Iduarte a huir de Villahermosa. La huida familiar, desde Tabasco y Campeche hasta Yucatán, marca un hito biográfico que dejará una profunda huella en la vida

\footnotetext{
126 IdUARTe, Un niño en la Revolución Mexicana, p. 26.

127 Iduarte, Un niño en la Revolución Mexicana, p. 27.

128 IdUarte, Un niño en la Revolución Mexicana, p. 27.

129 Iduarte, Un niño en la Revolución Mexicana, p. 7.

130 Iduarte, Un niño en la Revolución Mexicana, p. 74.
} 
de Iduarte: "Terminaba un ciclo de mi vida y se iniciaba otro [...] de vida mexicana, inquieta, febril, accidentada". ${ }^{131}$ Iduarte concibe la Revolución como una fuerza purificadora que le enseña "a vivir sin arraigos burgueses, sin conservatismos sentimentales". ${ }^{132}$ Sintomáticamente, en Lerma, Campeche, se hace amigo del ejército revolucionario allí acampado. Los soldados le hablan de la igualdad de todos los seres humanos, sobre la cual sus arrogantes primos de Mérida, Yucatán, no pueden más que reírse. Pero Iduarte está seguro de que igualmente van "a ser empobrecidos y humanizados" ${ }^{133}$ Recuerda la huida como un "turismo hambriento". ${ }^{134}$ El hambre y la escasez material provocados por la Revolución hacen que Iduarte cambie su forma de ser. Poco a poco empieza a distanciarse del mundo que aún extraña el pasado porfirista. "Empecé a sentirme diferente”, ${ }^{135}$ recuerda. “ ¿No era yo, ya, el amigo de los soldados de Lerma?”, ${ }^{136}$ pregunta al lector retóricamente. Pero con su regreso a Tabasco, en 1917, su "innato porfirismo" 137 es despertado de nuevo. A esto contribuyen no sólo sus parientes con sus anécdotas sobre la pasada grandeza familiar sino, sobre todo, la escuela "donde iban [...] a remachar con agravios y con desdenes mi admiración por el pecho enmedallado de don Porfirio". ${ }^{138}$

131 IdUarte, Un niño en la Revolución Mexicana, p. 44.

132 Iduarte, Un niño en la Revolución Mexicana, p. 62.

${ }^{133}$ IDUARTE, Un niño en la Revolución Mexicana, p. 68.

${ }_{134}$ Iduarte, Un niño en la Revolución Mexicana, p. 71.

135 IdUarte, Un niño en la Revolución Mexicana, p. 65.

136 IdUarte, Un niño en la Revolución Mexicana, p. 65.

137 IdUarte, Un niño en la Revolución Mexicana, p. 80.

138 Iduarte, Un niño en la Revolución Mexicana, p. 80. 
Iduarte describe la división del movimiento revolucionario en Tabasco, donde antiguas oposiciones ideológicas pierden visiblemente su importancia por la influencia corrompida del dinero y del poder. La revolución corrompida consolida su reaccionarismo infantil.

El traslado de la familia a la ciudad de México por la enfermedad de una de sus hermanas, no cambia la opinión política del joven tabasqueño, ya que allí se encuentra con la nueva "aristocracia"139 revolucionaria que, abiertamente cínica, ostenta su riqueza sin vergüenza. Iduarte y su familia reaccionan con indiferencia. "Mi vida, nuestra vida," recuerda, "seguía aparte, espectadora a secas de las tragedias de la Revolución, y ciega y sorda ante sus justicias. Eramos todavía - qué duda cabe - porfiristas". ${ }^{140}$ En adelante, explica: "Yo no podía ser revolucionario porque no era ni pícaro, ni cruel, ni traidor. Yo era reaccionario porque quería que todos los hombres fueran iguales [...], y que los que mandaran fueran hombres cultos, honrados y leales". ${ }^{141}$ Iduarte contrapone a la Revolución la imagen embellecida de un Porfirio Díaz intachable. Interrumpe la narración para confesar al lector: "Con este bagaje de errores llegué a todos los extremos". ${ }^{142}$ Iduarte sentía la necesidad de justificarse cuando escribió el texto. La justificación es un acto de habla muy típico en las narraciones autobiográficas. Un niño en la Revolución Mexicana, en conjunto, se puede concebir como un intento del autor de justificarse. Al escribir, Iduarte rinde cuentas a sí mismo y al lector de cómo podía admirar a

\footnotetext{
139 IdUARTe, Un niño en la Revolución Mexicana, p. 131.

140 IdUARTe, Un niño en la Revolución Mexicana, p. 139.

141 IdUarte, Un niño en la Revolución Mexicana, pp. 139-140.

142 Iduarte, Un niño en la Revolución Mexicana, p. 157.
} 
Porfirio Díaz y negar los resultados positivos de la Revolución. Se disculpa tanto con su niñez como con su ignorancia.

En el contexto del debate sobre la crisis y la muerte de la Revolución, Un niño en la Revolución Mexicana, que ofrece una visión pesimista de la Revolución, cobra una fuerza crítica más generalizada, ya que el texto se puede leer igualmente como una crítica de la corrupción de los regímenes de la Revolución a mediados del siglo xx. La confesión revolucionaria de Iduarte, llevada a cabo en el acto autobiográfico, le concedió al texto, además, cierta legitimidad. Como revolucionario declarado Iduarte está en una posición de criticar justificadamente a la Revolución. Pero hay que precisar; no criticó el movimiento revolucionario mismo, sino los caminos equivocados que tomó y a la dirigencia corrupta de Tabasco. Una crítica tal podría resultar actual y políticamente explosiva por la corrupción amplia presente durante el régimen de Miguel Alemán Valdés (1946-1952) quien, por cierto, fue compañero de Iduarte en la Universidad Nacional. ${ }^{143}$

El entusiasmo de Iduarte por Porfirio Díaz disminuye cuando entra en la Escuela Nacional Preparatoria. Ahora bien, este proceso es gradual. Al principio mantiene su postura poco crítica respecto al personaje. En un acto demostrativo, cuelga un enorme retrato de su héroe encima de su escritorio. Pero, visiblemente, Porfirio Díaz empieza a ser menos admirado por el joven estudiante. No son las clases sino sus amistades estudiantiles las que le abren los ojos en cuanto a las conquistas revolucionarias. A este cambio en la

${ }_{143}$ Respecto a la corrupción bajo el régimen de Alemán véase, NibLo, Mexico in the 1940s, pp. 253-310. 
conciencia política de Iduarte contribuye también una lectura desenfrenada de libros variados que pasan por su mesa - siempre bajo la mirada atenta de Porfirio Díaz.

En general, la lectura y los libros juegan un papel importante en Un niño en la Revolución Mexicana; acompañan, fomentan y reflejan el cambio de conciencia de Iduarte. Destacar el acto de lectura es, por cierto, una característica fundamental de la escritura autobiográfica en América Latina. Según Molloy, "el encuentro del yo con el libro es crucial: a menudo se dramatiza la lectura, se la evoca en cierta escena de la infancia que de pronto da significado a la vida entera”. ${ }^{144}$ Desde sus primeros años, Iduarte está rodeado de libros: "Jugué con Spencer, Comte, Giddings, Ferri y Lombroso“, comenta, "haciendo casas y puentes, castillos y fortalezas". ${ }^{145}$ Así subraya no sólo su afinidad para la lectura como hombre de letras, sino también perfila su origen intelectual.

La primera lectura de Iduarte no es una obra clásica del canon europeo, como en muchas otras autobiografías latinoamericanas, sino un libro de texto: La patria mexicana de Gregorio Torres Quintero. ${ }^{146}$ El libro, que presenta la historia mexicana desde la prehistoria hasta el presente de entonces, ayudó durante décadas a formar una identidad nacional. Se seguía empleando incluso en los años treinta, aunque contradijera algunos de los principios fundamentales de la educación socialista. ${ }^{147} \mathrm{El}$ texto ofrece una interpretación

144 Molloy, Acto de presencia, p. 28.

145 IdUARTe, Un niño en la Revolución Mexicana, p. 12.

146 Torres Quintero, La patria mexicana. Iduarte lo llama erróneamente 'Historia Patria'.

147 Galván Lafraga, “Arquetipos, mitos y representaciones”, particularmente pp. 163-165 y 174-175. 
liberal de la historia nacional. La lectura del texto provocó en Iduarte "el primer entusiasmo intelectual de mi vida". ${ }^{148}$ Con su primo, Carlitos Marín Foucher, se sube al techo de la casa de los vecinos para leer las hazañas de los héroes nacionales. Iduarte juzga al respecto:

La escuela primaria nos hacía patrioteros. Odiábamos a los españoles por españoles, con especial repugnancia para Pedro de Alvarado, el cruel Tonatiuh de las matanzas de indios; adorábamos a Cuauhtémoc, que defendió la gran Tenochtitlán y que cuando tuvo que rendirse a [Hernán] Cortés, le pidió que lo matara con su propio puñal [...]. Nos sonrojaba la sola mención del nombre de Moctezuma, de la Malinche y de los tlaxcaltecas, que habían traicionado a su patria. Nos indignaba y dolía la inteligencia y la audacia de Hernán Cortés [...] Y nuestra alegría estallaba cuando se acercaba la guerra de Independencia. ${ }^{149}$

La escena representa la iniciación de Iduarte en la comunidad nacional imaginada mediante el aprendizaje del mito liberal. Mediante su reproducción, aunque sea con distancia irónica, Iduarte transmite su pertenencia a la nación mexicana.

Para Iduarte, Porfirio Díaz se vuelve, con el tiempo, en un problema que demanda solución. En un acto simbólico Iduarte finalmente decide bajar el retrato, después de que no ha querido invitar a un amigo a entrar en su habitación por vergüenza. Lo enrolla y lo oculta detrás de su armario hasta que un pariente fue a recogerlo. "Era [...] el epílogo

148 IdUarte, Un niño en la Revolución Mexicana, p. 75.

149 Iduarte, Un niño en la Revolución Mexican, pp. 75-76. 
de la existencia escrutadora del niño y el preámbulo de la vida agitada y dolorosa del hombre". ${ }^{150} \mathrm{El}$ acto simbólico no sólo termina la infancia de Iduarte sino también su purificación moral y política. Iduarte declara: "Ya no era yo porfirista". ${ }^{151} \mathrm{Al}$ final de la narración, Iduarte se ha encontrado tanto consigo mismo como con la revolución mexicana. Después de esta escena la narración se interrumpe. Esto de ningún modo es gratuito, sino que es una característica que marca el tipo de la narración de conversión, ya que con el cambio de conciencia, el objetivo último de la biografía y del texto es alcanzado. Por el momento, no parece merecer la pena contar la continuación de la vida. ${ }^{152}$

Un niño en la Revolución Mexicana es frecuentemente comparado con el Ulises criollo. ${ }^{153}$ Sin embargo, las obras autobiográficas se distinguen en un aspecto fundamental: a diferencia de Vasconcelos, Iduarte no cuenta una vida única, excepcional y ejemplar, sino una vida representativa, marcada por la violencia, el hambre y el sufrimiento; no cuenta una vida de voluntad propia, sino una vida determinada por la Revolución. En la escritura autobiográfica, Iduarte intenta superar el abismo que le separa de su patria. Por eso no puede insistir en la unicidad de su vida, más bien, tiene que preocuparse por resaltar la posibilidad de generalizar su biografía, es decir, la posibilidad de unirla con las experiencias colectivas. Para lograrlo recurre a acon-

150 IdUarte, Un niño en la Revolución Mexicana, p. 167.

151 IdUarte, Un niño en la Revolución Mexicana, p. 167.

152 Véase Wagner-EgelhaAf, Autobiographie, pp. 113-114. De manera significativa Iduarte publicó su segunda narración autobiográfica, $E l$ mundo sonriente, después de 17 años, en 1968.

153 Véase, por ejemplo, Aguilar, “Andrés Iduarte”. 
tecimientos históricos que se han grabado en la memoria colectiva de la nación mexicana y que han conseguido un carácter simbólico. Iduarte cuenta, por ejemplo, que cuando era niño imitaba con su abuela la ejecución de Maximiliano de Austria y los generales conservadores Miguel Miramón y Tomás Mejía con unos muñecos. ${ }^{154}$ Esa escena simboliza el fin del imperio de Maximiliano y la derrota del conservadurismo mexicano; marca un momento crucial en la historia liberal mexicana. Iduarte enlaza así las historias micro y macro. En otra parte se presenta al lector como testigo del funeral de Venustiano Carranza, "el único honrado”. ${ }^{155}$ El lector llega a saber que Iduarte estuvo allí presente y de esa manera formó parte de la historia patria. Además, la pretendida representatividad de la biografía de Iduarte se manifiesta perfectamente en el título del libro: él no es un héroe mítico, no es un Ulises criollo, sino un niño en la revolución mexicana.

Un niño en la Revolución Mexicana se puede leer igualmente como una alegoría de la historia nacional de México. Desde la perspectiva filosófica, observa Keller, a Iduarte y la Revolución "se [les] presenta el mismo problema: cómo atender al pasado”. ${ }^{156}$ Tanto como Iduarte, la sociedad mexicana tuvo que llevar a cabo una transformación identitaria ante la Revolución. El porfiriato, que antes se había visto como la culminación de la historia liberal, perdió su legitimidad histórica. En el mito revolucionario, el porfiriato fue reinterpretado: le dieron el significado de dictadura y lo

\footnotetext{
154 Véase Iduarte, Un niño en la Revolución Mexicana, p. 15.

155 IdUARTe, Un niño en la Revolución Mexicana, p. 139.

156 Keller, “El niño en la Revolución Mexicana”, p. 151.
} 
identificaron con la Reacción. En cambio, la Revolución fue integrada en la tradición de la Independencia y la Reforma y declarada el nuevo fin de la historia liberal. ${ }^{157}$ "El descendimiento de don Porfirio" - así se llama el título del último capítulo de la narración autobiográfica - fue tanto para Iduarte como para la sociedad mexicana un acto doloroso, no obstante, inevitable.

\section{CONCLUSIONES}

La escritura de Iduarte estuvo marcada por la nostalgia de un emigrante "que se fue, tanto en la satisfacción de servir a México con fidelidad - en la prensa, en la Universidad, en la calle-, como en el temor de haberlo servido menos de como hubiera ocurrido bajo su cielo" ${ }^{158}$ El escritor tabasqueño estuvo comprometido con su patria y se preocupó profundamente por la pérdida temida de sus raíces culturales. Nunca dejó “de oír la voz de José Martí: 'un hombre en el extranjero es como un árbol en la mar'”. ${ }^{159}$ Con añoranza sus reflexiones regresaban con frecuencia al México revolucionario, en el que había pasado su niñez y su juventud. Para él la escritura significó un medio oportuno para asegurase de su identidad y presentarse como un mexicano intachable. Sus narraciones autobiográficas jugaron un papel particularmente importante en este empeño.

En este sentido, la publicación de Un niño en la Revolución Mexicana representó un acto de habla, un acto de

157 Véase Benjamin, La Revolución, pp. 22 y 42-45.

${ }^{158}$ IDUARTE, "Nota a la presente edición" (1984), p. vii.

159 IdUarte, “Nota a la presente edición” (1984), p. viii. 
comunicación que buscaba el reconocimiento social. Iduarte asoció su propia biografía con la historia de su patria a fin de comunicar su pertenencia a la nación mexicana. El escritor tabasqueño confesó públicamente haber sido un niño porfirista y narró su propia transformación en un hombre revolucionario. El enunciado principal de la narración autobiográfica dice ni más ni menos que el tabasqueño llegó de la Reacción a la Revolución - alcanzó a integrarse en la nueva sociedad revolucionaria.

Declararse en favor de la Revolución permitió a Iduarte narrar desde una posición legitima una historia de violencia y sufrimiento; pudo describir las contradicciones y el desgarramiento interior del movimiento revolucionario y exhibir la corrupción de sus dirigentes en Tabasco. No faltó la mención negativa del futuro hombre fuerte de Tabasco - Tomás Garrido Canabal - . Por razones familiares, Iduarte fue enemigo del gobernador del estado tropical y lo combatía con toda su fuerza verbal. La complicada situación política en el Tabasco de los años veinte y treinta del siglo pasado, de la cual fue víctima la familia de Iduarte, tuvo una influencia muy interesante en la historia de la publicación de Un niño en la Revolución Mexicana. Por prudencia política, Iduarte le dio al texto un "carácter de novela” y cambió los nombres de sus parientes y también el de Garrido. No obstante, frente al cambio político en Tabasco, los sustituyó poco a poco por los nombres auténticos, de manera que Un niño en la Revolución Mexicana se transformó de una novela autobiográfica en una auténtica autobiografía.

Un niño en la Revolución Mexicana es un ejemplo para demostrar que las narraciones autobiográficas no son ni testimonios objetivos ni juegos de palabras posmodernos, sino 
textos que forman parte de procesos comunicativos e históricos de construcción tanto de identidades personales como de identidades colectivas. Por eso, vale la pena analizarlos desde una nueva perspectiva, una perspectiva que reconozca y se sirva de las particularidades de este tipo de fuentes. La nueva historia cultural y la pragmática lingüística podrían ofrecer los requisitos necesarios para este empeño. En todo caso, muchísimas narraciones autobiográficas mexicanas esperan su descubrimiento historiográfico; representan un campo de estudio fértil que deja aún mucho por indagar.

\section{REFERENCIAS}

Agustín de Hipona

Confesiones, Madrid, Gredos, 2010.

Alazraki, Jaime, Roland Grass y Russel O. Salmon (comps.)

Homenaje a Andrés Iduarte. Ofrecido por sus amigos y discipulos, Clear Creek, Ind., American Hispanist, 1976.

Alcubierre Moya, Beatriz y Tania Carreño King

Los niños villistas. Una mirada a la historia de la infancia en México, 1900-1920, México, Instituto Nacional de Estudios Históricos de la Revolución Mexicana, 1997.

Anaya Merchant, Luis, Marcos T. Águila M. y Alberto Enríquez Perea (comps.)

Personajes, ideas, voluntades. Políticos e intelectuales mexicanos en los años treinta, México y Cuernavaca, Mor., Miguel Ángel Porrúa, Universidad Autónoma del Estado de Morelos, 2011.

Anderson, Benedict

Comunidades imaginadas. Reflexiones sobre el origen y la difusión del nacionalismo, México, Fondo de Cultura Económica, 1993. 
AristizÁBAL, Catherine

Autodocumentos hispanoamericanos del siglo XIX. Fuentes personales y análisis histórico, Münster, LIT Verlag, 2012.

Assmann, Jan

Das kulturelle Gedächtnis. Schrift, Erinnerung und politische Identität in früben Hochkulturen, Múnich, C.H. Beck, 1992.

Avilés Fabila, René

“Un niño en la Revolución Mexicana”, en Casa del Tiempo, 53 (2012), pp. 22-27.

BARRóN, Luis

Historias de la Revolución Mexicana, México, Fondo de Cultura Económica, Centro de Investigación y Docencia Económicas, 2004.

BeEr, Gabriella de

“Visión de España en la obra de Andrés Iduarte”, en Cuadernos Americanos, 9 (1980), pp. 130-136.

Benjamin, Thomas

La Revolución. Mexico's Great Revolution as Memory, Myth, and History, Austin, Tex., University of Texas Press, 2000.

Beteta, Ramón

Jarano, México, Fondo de Cultura Económica, 1966.

Breuer, Ulrich y Beatrice SANDbERG

"Einleitung", en Ulrich Breuer y Beatrice SANDBERG (comps.), Autobiographisches Schreiben in der deutschsprachigen Gegenwartsliteratur, Múnich, Iudicium, 2006, t. I, pp. 9-16.

Bruce-NovoA, Juan

"La novela de la Revolución Mexicana. La topología del final”, en Hispania, 74 (1991), pp. 36-44. 
Buchenau, Jürgen y William H. Beezley (comps.)

State Governors in the Mexican Revolution, 1910-1952. Portraits in Conflict, Courage, and Corruption, Lanham, Maryl., Rowman \& Littlefield Publishers, 2009.

CÁrdenas, Hipólito D.

Mi padre y yo, México, Stylo, 1962.

Carreño King, Tania (comp.)

Infancia y revolución, México, Consejo Nacional para la Cultura y las Artes, 2010.

Carretero, Anselmo

“Andrés Iduarte en España”, en Grass (comp.), 1975, pp. 27-37.

Contreras Pérez, Gabriela

Rodulfo Brito Foucher (1899-1970). Un politico al margen del régimen revolucionario, México, Universidad Nacional Autónoma de México, Plaza y Valdes, 2008.

"Rodulfo Brito Foucher: 'La Revolución era ya un pudridero moral'”, en Anaya Merchant, Aguila M. y Enríquez PeREA (comps.), 2011, pp. 147-170.

Córdova, Arnaldo

"La mitología de la Revolución Mexicana", en Florescano (comp.), 2005, pp. 27-32.

Cornelißen, Christoph

"Was heißt Erinnerungskultur? Begriff, Methoden, Perspektiven", en Geschichte in Wissenschaft und Unterricht, 54 (2003), pp. 548-563.

Depkat, Volker

"Plädoyer für eine kommunikationspragmatische Erneuerung der Quellenkunde”, en MERziger et al. (comps.), 2010, pp. 205-221. 
"Zum Stand und zu den Perspektiven der Autobiographieforschung in der Geschichtswissenschaft", en Bios. Zeitschrift für Biographieforschung, Oral History und Lebensverlaufsanalysen, 23:2 (2010), pp. 170-187.

Díaz Arciniega, Víctor

"La voz: el eco. Vasconcelos: lección de historia y vida", en FeLl (comp.), 2000, pp. 732-775.

Duve, Thomas et al. (comps.)

Jabrbuch für Geschichte Lateinamerikas/Anuario de Historia de America Latina, 47 (2010).

Eineigel, Susanne K.

"Distinction, Culture, and Politics in Mexico City's Middle Class, 1890-1940", tesis de doctorado en historia, Calif., University of Maryland, 2011.

EsPejel López, Laura (comp.)

Estudios sobre el zapatismo, México, Instituto Nacional de Antropología e Historia, 2000.

Fell, Claude (comp.)

José Vasconcelos: Ulises criollo, Nanterre, Francia, Université Paris X, Signatarios del Acuerdo Archivos, ALLCA XX, 2000.

Ferreira de Cassone, Florencia (comp.)

Memoria y autobiografía en Iberoamérica, Buenos Aires, Dunken, 2008.

Florescano, Enrique (comp.)

Mitos mexicanos, México, Taurus, 2005.

Galván Lafraga, Luz Elena

"Arquetipos, mitos y representaciones en libros de historia patria (1934-1939)”, en Galván Lafraga, Castañeda García y Martínez Moctezuma (comps.), 2004, pp. 163-176. 
Galván Lafraga, Luz Elena, Carmen Castañeda García y Lucía Martínez Moctezuma (comps.)

Lecturas y lectores en la historia de México, México, Centro de Investigaciones y Estudios Superiores en Antropología Social, Universidad del Estado de Morelos, El Colegio de Michoacán, 2004.

GAONA, Rafael

Andrés y Diego en la muerte de Frida, Tuxtla Gutiérrez, Chs., Consejo Estatal para la Cultura y las Artes en Chiapas, 1999.

Garizurieta, César

Recuerdos de un niño de pantalón largo, México, Ruta, 1952.

Gordon, Samuel (comp.)

Estudios de literatura mexicana. Segundas Jornadas Internacionales 'Carlos Pellicer' sobre literatura tabasqueña, Villahermosa, Tab., Gobierno del Estado de Tabasco, Instituto de Cultura de Tabasco, 1992.

Grass, Roland (comp.)

Andrés Iduarte. Un homenaje al escritor y maestro ofrecido por amigos y discípulos. Ensayos, testimonios, poemas con un álbum de fotografías, Macomb, Ill., Western Illinois University, 1975.

Guerrero Flores, David

"La valoración del trabajo infantil en México (1910-1920)", en MAYer (comp.), 2007, t. 1, p. 121-147.

GüNTHER, Dagmar

“'And now for something completely different...' Prolegomena zur Autobiographie als Quelle der Geschichtswissenschaft", en Historische Zeitschrift, 272 (2001), pp. 25-61.

Halbwachs, Maurice

Das kollektive Gedächtnis, Frankfurt M., Fischer, 1985. 
Hale, Charles A.

"Los mitos políticos de la nación mexicana. El liberalismo y la revolución”, en Historia Mexicana, 46:4 (184) (abr.-jun. 1997), pp. 821-837.

HARPer, Kristin A.

“Tomás Garrido Canabal of Tabasco. Road Building and Revolutionary Reform", en Buchenau y BeEzley (comps.), 2009, pp. 109-121.

Heinze, Carsten

"Der paratextuelle Aufbau der Autobiographie", en Bios. Zeitschrift für Biographieforschung, Oral History und Lebensverlaufsanalysen, 20:1 (2007), pp. 19-39.

“Autobiographie und zeitgeschichtliche Erfahrung. Über autobiographisches Schreiben und Erinnern in sozialkommunikativen Kontexten", en Geschichte und Gesellschaft, 36 (2010), pp. 93-128.

Hobsbawm, Eric y Terence Ranger (comps.)

The Invention of Tradition, Cambridge y Nueva York, Cambridge University Press, 1983.

IDUARTE, Andrés

"El mundo primero. Capítulo de la novela Tabasco (un niño en la Revolución Mexicana)", en Hora de España, 12 (1937), pp. 82-94.

Un niño en la Revolución Mexicana, México, Ruta, 1951.

El mundo sonriente, México, Fondo de Cultura Económica, 1968.

Child of the Mexican Revolution, edición y traducción de James F. Shearer, Nueva York, Washington y Londres, Praeger, 1971.

“Nota a la presente edición”, en IdUarte (comp.), 1982, p. vii.

“Nota a la presente edición”, en IdUARTE (comp.), 1984, pp. vii-viii. 
“Presencia de los ausentes", en IdUarte (comp.), 1984, pp. 21-24.

“Carta a un buen amigo", en Iduarte (comp.), 1984, pp. 41-48.

“México en Nueva York”, en Iduarte (comp.), 1984, pp. 69-74.

“El 20 de noviembre”, en IdUarte (comp.), 1984, pp. 94-99.

“Nuestra Revolución Mexicana”, en Iduarte (comp.), 1984, pp. 100-105.

“El legado de la Revolución”, en IDUARTE (comp.), 1984, pp. 111-116.

“Don Pedro de Alba y su tiempo", en IdUarte (comp.), 1984, pp. 5-36.

“El sultán rojo”, en IDUARTE (comp.), 1986, pp. 64-66.

Un niño en la Revolución Mexicana, México, Consejo Nacional para la Cultura y las Artes, 2010.

IDUARTE, Andrés (comp.)

'Un niño en la Revolución Mexicana' seguido de 'El mundo sonriente', México, Joaquín Mortiz, 1982.

Semblanzas, México, Joaquín Mortiz, 1984.

México en la nostalgia, México, Joaquín Mortiz, 1984.

Preparatoria, México, Joaquín Mortiz, Secretaría de Educación Pública, 1986.

Jörgensen, Beth E.

The Writing of Elena Poniatowska. Engaging dialogues, Austin, Tex., University of Texas Press, 1994.

Documents in Crisis. Nonfiction Literatures in Twentieth-Century Mexico, Albany, State University of New York Press, 2011.

Keller, Garry D.

"El niño en la Revolución Mexicana. Nellie Campobello, Andrés Iduarte y César Garizurieta", en Cuadernos Americanos, 170 (1970), pp. 142-151. 
Keller, Gary D. y Karen S. Van Hooft

"Las actividades políticas de los estudiantes mexicanos durante la década 1920-1930. Un examen de fuentes literarias (Andrés Iduarte, Mauricio Magdaleno, José Vasconcelos)", en Alazraki, Grass y O. Salmon (comps.), 1976, pp. 201-215.

Knight, Alan

"The Myth of the Mexican Revolution", en Past and Present, 209 (2010), pp. 223-273.

Kolar, Fabio

"Erinnern, erzählen, bekennen: Eine Kindheit in der mexikanischen Revolution", en Netz+Werk. Junge Hamburger Geschichte online, http://netzwerk.hypotheses.org/1980 (consultado el 23 de abril de 2015).

Krusenstjern, Benigna von

Was sind Selbstzeugnisse? Begriffskritische Überlegungen anhand von Beispielen aus dem 17 Jahrhundert”, en Historische Antropologie, 2 (1994), pp. 462-471.

LeAL, Luis

"Iduarte y la Revolución Mexicana", en Revista Hispánica Moderna, 20:1/2 (1954), pp. 76-79.

Lejeune, Philippe

El pacto autobiográfico y otros estudios, Madrid, MegazulEndymion, 1994.

López Bonilla, Guadalupe y Carmen Pérez Fragoso

“Discurso", en Szurmuk y McKee Irwin (comps.), 2009, pp. 89-92.

Mandujano Jacobo, Pilar

“Andrés Iduarte”, en Ocampo (comp.), 1997, t. IV, pp. 167-171. 
Martínez Assad, Carlos

El laboratorio de la Revolución. El Tabasco garridista, México, Siglo Veintiuno editores, 1979.

Breve historia de Tabasco, México, El Colegio de México, Fondo de Cultura Económica, Fideicomiso Historia de las Américas, 2006.

Mayer, Alicia (comp.)

México en tres momentos: 1810-1910-2010. Hacia la conmemoración del Bicentenario de la Independencia y del Centenario de la Revolución Mexicana. Retos y perspectivas, México, Universidad Nacional Autónoma de México, 2007, 2 tomos.

Merziger, Patrick et al. (comps.)

Geschichte, Öffentlichkeit, Kommunikation. Festschrift für Bernd Sösemann zum 65. Geburtstag, Stuttgart, Steiner, 2010.

Meyer, Eugenia

“¿Dónde están los niños? Reflexiones para una historia de la infancia durante la Revolución”, en EsPejel López (comp.), 2000, pp. 439-459.

Molloy, Sylvia

Acto de presencia. La escritura autobiográfica en Hispanoamérica, México, El Colegio de México, Fondo de Cultura Económica, 1996.

Morales, Dionicio

"En el centenario de Andrés Iduarte", http://www.reneavilesfabila.com.mx/universodeelbuho/91/91-encarte.pdf (consultado el 23 de abril de 2015).

MüCKe, Ulrich

"Introducción. Escritura autobiográfica e historia en Hispanoamérica", en Jabrbuch für Geschichte Lateinamerikas/ Anuario de Historia de America Latina, 47 (2010), pp. 1-9. 
"Autobiographisches Schreiben und Kolonialismus in Peru", en Ulbrich, Medick y Schaser (comps.), 2012, pp. 201-225.

Mücke, Ulrich y Marcel VelázQuez (comps.)

Autobiografía del Perú republicano. Ensayos sobre historia y la narrativa del yo, Lima, Biblioteca Nacional del Perú, 2015.

Niblo, Stephen R.

Mexico in the 1940s. Modernity, Politics, and Corruption, Wilmington, Del., Scholarly Resources, 2001.

Núñez Guzmán, J. Trinidad

Mi infancia en la Revolución. Apuntes de un muchacho pueblerino, México, Libro Mex, 1960.

OBRegón, Álvaro

Ocho mil kilómetros en campaña, México, Consejo Nacional para la Cultura y las Artes, 2008.

Ocampo, Aurora M. (comp.)

Diccionario de escritores mexicanos, México, Universidad Nacional Autónoma de México, 1997.

Ocampo Ramírez, Pedro

“Andrés Iduarte. Un hombre en la revolución de las ideas", en GORDON (comp.), 1992, pp. 159-165.

Orestes Aguilar, Héctor

“Andrés Iduarte y José Vasconcelos. Crónicas de infancia”, en GORDON (comp.), 1992, pp. 167-174.

Paúl Arranz, María del Mar

"La novela de la Revolución Mexicana y la revolución en la novela”, en Revista Iberoamericana, Lxv: 186 (ene.-mar. 1999), pp. 49-57. 
Picón Salas, Mariano

“Un gran testimonio mexicano", en IDUARTE (comp.), 1982, pp. 227-230.

Ramos, Raymundo

Memorias y autobiografías de escritores mexicanos, México, Universidad Nacional Autónoma de México, 1967.

RAPHAEL, Lutz

Geschichtswissenschaft im Zeitalter der Extreme. Theorien, Methoden, Tendenzen von 1900 bis zur Gegenwart, Múnich, C. H. Beck, 2003.

Reséndiz García, Ramón

"Del nacimiento y muerte del mito político llamado Revolución Mexicana. Tensiones y transformaciones del régimen político, 1914-1994”, en Estudios Sociológicos, 23:67 (2005), pp. 139-183.

Reyes, Graciela

La pragmática lingüística. El estudio del uso del lenguaje, Barcelona, Montesinos, 1994.

Ridgeway, Stan

"Monoculture, Monopoly, and the Mexican Revolution. Tomás Garrido Canabal and the Standard Fruit Company in Tabasco (1920-1935)", en Mexican Studies/Estudios Mexicanos, 17:1 (2001), pp. 143-169.

Rовв, James W.

"México en la nostalgia", en Universidad de México, 40:414 (1985), pp. 29-34.

Rodríguez Coronel, Rogelio

“Andrés Iduarte. Un escritor de la revolución”, en RoDRíGUEZ Coronel (comp.), 1997, pp. 105-114. 
Rodríguez Coronel, Rogelio (comp.)

Espacios críticos. Sobre novelas y procesos literarios en Latinoamérica, Panamá, Portobelo, 1997.

Ross, Stanley R. (comp.)

Is the Mexican Revolution Dead?, Nueva York, Knopf, 1966.

Sacoto, Antonio

“Andrés Iduarte. Camino y luz”, en Grass (comp.), 1975, pp. 67-78.

Salmerón Sanginés, Pedro

"Los historiadores y la guerra civil de 1915. Origen y persistencia de un canon historiográfico", en Historia Mexicana, LVIII: 4 (232) (abr.-jun. 2009), pp. 1305-1368.

Schaser, Angelika

“Einleitung”, en Angelika SCHASER (comp.), Erinnerungskartelle. Zur Konstruktion von Autobiographien nach 1945, Bochum, Winkler, 2003, pp. 7-16.

Sosenski, Susana y Elena Jackson Albarrán (comps.)

Nuevas miradas a la historia de la infancia en América Latina. Entre prácticas y representaciones, México, Universidad Nacional Autónoma de México, 2012.

Sosenski, Susana y Mariana Osorio Gumá

"Memorias de infancia. La Revolución mexicana y los niños a través de dos autobiografías", en Sosenski y Jackson AlBARRÁN (comps.), 2012.

Szurmuk, Mónica y Robert McKee Irwin (comps.)

Diccionario de estudios culturales latinoamericanos, México, Siglo Veintiuno editores, Instituto de Investigaciones Dr. José María Luis Mora, 2009. 
Torres Quintero, Gregorio

La patria mexicana. Elementos de historia nacional, México, Herrero Hermanos Sucesores, 1920.

Ulbrich, Claudia, Hans Medick y Angelika Schaser

"Selbstzeugnis und Person. Transkulturelle Perspektiven", en Ulbrich, Medick y Schaser (comps.), 2012, pp. 1-19.

Ulbrich, Claudia, Hans Medick y Angelika Schaser (comps.)

Selbstzengnis und Person. Transkulturelle Perspektiven, Colonia, Böhlau, 2012.

URías Horcasitas, Beatriz

"Autoritarismo y violencia. La perspectiva del conservadurismo hispanófilo. El caso de Rodulfo Brito Foucher (1938)", en Estudios Sociológicos, 32:96 (2014), pp. 573-592.

VAN Young, Eric

"The New Cultural History Comes to Old Mexico", en The Hispanic American Historical Review, 79:2 (1999), pp. 211-247.

Wagner-EgelhaAf, Martina

Autobiographie, Stuttgart y Weimar, Metzler, 2005.

Woods, Richard D.

"Mexican Autobiography within Mexican Literature", en Revista Interamericana de BibliografíalInteramerican Review of Bibliography, 41 (1991), pp. 3-14.

"Mexican Autobiography. An Essay and Annotated Bibliography”, en Hispania, 77:4 (1994), pp. 750-802.

Autobiographical Writings on Mexico. An Annotated Bibliography of Primary Sources, Jefferson, N.C., McFarland \& Co., 2005. 
Zermeño Padilla, Guillermo

“Toribio Esquivel Obregón: del hombre público al privado: 'Memorias' a la sombra de la revolución”, en Secuencia, 21 (1991), pp. 65-81. 
